Article

\title{
Phytochemical Profile, Antioxidant and Wound Healing Potential of Three Artemisia Species: In Vitro and In Ovo Evaluation
}

\author{
Daliana Minda ${ }^{1,2,+}$, Roxana Ghiulai ${ }^{2,3,+}$, Christian Dragos Banciu ${ }^{4, *}$, Ioana Zinuca Pavel 1,2,*(D), \\ Corina Danciu ${ }^{1,2} \mathbb{D}$, Roxana Racoviceanu ${ }^{2,3}{ }^{(D}$, Codruta Soica ${ }^{2,3}$, Oana Daniela Budu ${ }^{4}$, Delia Muntean ${ }^{5} \mathbb{D}_{\text {, }}$ \\ Zorita Diaconeasa ${ }^{6}$ (D), Cristina Adriana Dehelean ${ }^{2,7}$ and Stefana Avram ${ }^{1,2}$ (D)
}

Citation: Minda, D.; Ghiulai, R.; Banciu, C.D.; Pavel, I.Z.; Danciu, C.; Racoviceanu, R.; Soica, C.; Budu, O.D.; Muntean, D.; Diaconeasa, Z.; et al. Phytochemical Profile, Antioxidant and Wound Healing Potential of Three Artemisia Species:

In Vitro and In Ovo Evaluation. Appl. Sci. 2022, 12, 1359. https://doi.org/ 10.3390/app12031359

Academic Editor: Catarina Guerreiro Pereira

Received: 11 January 2022

Accepted: 25 January 2022

Published: 27 January 2022

Publisher's Note: MDPI stays neutral with regard to jurisdictional claims in published maps and institutional affiliations.

Copyright: (C) 2022 by the authors. Licensee MDPI, Basel, Switzerland. This article is an open access article distributed under the terms and conditions of the Creative Commons Attribution (CC BY) license (https:// creativecommons.org/licenses/by/ $4.0 /)$.
1 Department of Pharmacognosy, Faculty of Pharmacy, "Victor Babes" University of Medicine and Pharmacy Timisoara, Eftimie Murgu Square No. 2, RO-300041 Timişoara, Romania; daliana.minda@umft.ro (D.M.); corina.danciu@umft.ro (C.D.); stefana.avram@umft.ro (S.A.)

2 Research Center for Pharmaco-Toxicological Evaluations, Faculty of Pharmacy, "Victor Babes" University of Medicine and Pharmacy Timisoara, Eftimie Murgu Square No. 2, RO-300041 Timişoara, Romania; roxana.ghiulai@umft.ro (R.G.); babuta.roxana@umft.ro (R.R.); codrutasoica@umft.ro (C.S.); cadehelean@umft.ro (C.A.D.)

3 Department of Pharmaceutical Chemistry, Faculty of Pharmacy, "Victor Babes" University of Medicine and Pharmacy Timisoara, Eftimie Murgu Square No. 2, RO-300041 Timişoara, Romania

4 Department of Internal Medicine IV, Faculty of Medicine, “Victor Babes” University of Medicine and Pharmacy Timisoara, Eftimie Murgu Square No. 2, RO-300041 Timişoara, Romania; oanadaniela.budu@yahoo.ro

5 Department of Microbiology, Faculty of Medicine, "Victor Babes" University of Medicine and Pharmacy Timisoara, Eftimie Murgu Square No. 2, RO-300041 Timişoara, Romania; muntean.delia@umft.ro

6 Department of Food Science and Technology, Faculty of Food Science and Technology, University of Agricultural Science and Veterinary Medicine, Calea Manastur, 3-5, RO-400372 Cluj-Napoca, Romania; zorita.diaconeasa@gmail.com

7 Department of Toxicology, Faculty of Pharmacy, "Victor Babes" University of Medicine and Pharmacy Timisoara, Eftimie Murgu Square No. 2, RO-300041 Timişoara, Romania

* Correspondence: banciu.christian@umft.ro (C.D.B.); ioanaz.pavel@umft.ro (I.Z.P.)

+ These authors contributed equally to this work.

Abstract: Skin injuries, and especially wounds of chronic nature, can cause a major negative impact on the quality of life. New efficient alternatives are needed for wound healing therapy and herbal products are being investigated due to a high content of natural compounds with promising healing activity. For this purpose, we investigated three Artemisia species, Artemisia absinthium L. (AAb), Artemisia dracunculus L. (ADr) and Artemisia annua L. (AAn). Ethanolic extracts, containing different polyphenolic compounds, elicited strong antioxidant activities in the DPPH assay, comparable to ascorbic acid. Human ketratinocyte proliferation was stimulated and wound closure was enhanced by all three extracts at concentrations of $100 \mu \mathrm{g} / \mathrm{mL}$. The Artemisia extracts modulated angiogenesis by increasing vessel formation, especially following treatment with A. annua and A. dracunculus, extracts with a significantly higher content of chlorogenic acid. Good tolerability and anti-irritative effects were also registered in ovo, on the chorioallantoic membrane (CAM). The three Artemisia species represent promising low-cost, polyphenol-rich, antioxidant, safe alternatives for wound care treatment.

Keywords: Artemisia annua; Artemisia dracunculus; Artemisia absinthium; polyphenols; wound healing; keratinocytes; CAM assay

\section{Introduction}

The skin is our largest organ, an essential barrier towards the outer environment, a key protector of our organism from dehydration, pathogens, toxic chemicals, thermal 
deregulation. Its exposure and vulnerability are the source of frequent injuries. Repair and regeneration are extraordinary functions, being activated through unique cross-talk mechanisms of numerous cells, growth factors and cytokines [1]. The process of cutaneous wound healing can be divided into four overlapping phases: hemostasis, inflammation, proliferation/migration, and remodeling, involving vasoconstriction, platelet aggregation, antimicrobial effects, vascular leakiness, fibroblast proliferation, angiogenesis, collagen remodeling [2].

Unfortunately, the burden of worldwide vascular diseases, metabolic syndrome and aging has an impact on the rising number of patients with dysregulated healing wounds that can cause a major negative influence on the quality of life and on healthcare systems [3]. Despite important advances in wound care therapies, focused on skin repair and regeneration, there are still major limitations such as bacterial resistance and, especially, high costs. New efficient alternatives are desirable for wound healing therapy; traditional medicine is an important source of inspiration, since natural products were used as healing remedies from ancient times, and are still dominant therapeutic approaches in Asia, Africa or Latin America [1,2].

As a result of scientific progress, a large number of new active principles have been discovered, leading to an extensive knowledge of medicinal plants uses [4,5]. Artemisia species are included in the genus Artemisia, belonging to the Asteraceae family. These are aromatic, medicinal plants and culinary herbs [6]. Artemisia species are widespread in Asia, Europe and North America, in temperate, subtropical and cold regions [7]. Artemisia comprises about 500 species, including the three species that were selected for the present study: A. annua L. (AAn), A. absinthium L. (AAb), A. dracunculus L. (ADr). These species represent traditional remedies, being available in herbal shops.

The major bioactive types of phytocompounds that are described for Artemisia species are terpenoids, flavonoids, coumarins, acetylenes, caffeoylquinic acids and sterols [8-10]. A. annua, known as sweet wormwood is used as anti-malarial, anti-ulcer, anti-hyperlipidemic, anti-plasmodial, anti-convulsant, anti-inflammatory and anti-microbial remedy [11-13]. A. dracunculus, also called tarragon, a well-known culinary herb, was shown to possess antidiabetic effects due to the flavonoids in the composition [14]. Tarragon is also known as an analgesic, hypnotic, antiepileptic, anti-inflammatory and antipyretic, anticoagulant, antibacterial agent; more recent studies have proven its antioxidant, immunomodulating, anti-tumor activities, as well as hepatoprotective and hypoglycemic effects [15-17]. A. absinthium, or wormwood, has also been shown to possess several therapeutic effects: digestive, antiprotozoal, anthelmintic, antimicrobial, anti-inflammatory, cytotoxic, antioxidative, neuroprotective [18-22].

More recently, especially due to their polyphenolic content, Artemisia species were associated with healing potential, by reducing the number of inflammatory cells in the wounded area, with a positive impact on the progress of wound healing, improving the proliferation of human keratinocytes [23]. Still, there are not many studies that investigate the effect of the three Artemisia species regarding the underlaying mechanisms involved in the process of wound repair.

One important step in the process of tissue regeneration during the proliferative phase is represented by angiogenesis, the development of vessels from pre-existing ones, orchestrated by a sophisticated communication between cells, angiogenic factors and the surrounding tissues. Unfortunately, the process is mostly dysregulated in vascular diseases. Efforts are being directed toward the exploration of potential natural agents that can modulate the impaired reparative angiogenesis [24-27].

An experimental approach for this purpose is the chorioallantoic membrane (CAM) assay, considered an in vivo experimental alternative to animal models with advantages such as time, accessibility and costs. The method can be used to assess the angiogenic effects, but also to estimate the biocompatibility and the irritation potential of natural products $[28,29]$. 
In the present study, we investigated three Artemisia species available on the herbal market in Romania, A. annua, A dracunculus, A absinthium, regarding the phenolic content and profile of ethanolic extracts, next to in vitro antioxidant assessment, healthy keratinocyte viability and migration, as well as in vivo angiogenic and anti-irritative potential.

\section{Materials and Methods}

\subsection{Plant Materials and Extraction}

The plant material of the three Artemisia species in our study were purchased from herbal shops in Timisoara, Romania. All three species were represented by aerial parts of the plants, Artemisiae annuae herba (AAn), Dracunculi herba (ADr), Absinthii herba (AAb). The plant material of AAn and AAb were collected from Romania, while ADr, from Greece.

The dried plant material was grounded and stored in amber glass containers. Powdered dry plant material was extracted in ethanol 80\% $(v / v),(10 \mathrm{~g}$ dry weight/100 $\mathrm{mL})$ by maceration for $15 \mathrm{~min}$ at room temperature, followed by ultrasound assisted extraction using the ultrasonic bath (Falc LCD series), for $30 \mathrm{~min}$ at $50{ }^{\circ} \mathrm{C}, 800 \mathrm{~W}$ and $40 \mathrm{KHz}$.

All samples were filtered and extracts were concentrated to dryness in a rotary vacuum evaporator (Heidolph Laborota 4000, Schwalbach, Germany) at $50{ }^{\circ} \mathrm{C}$. Dried extracts (d.e.) were stored at $-20^{\circ} \mathrm{C}$ prior to use.

\subsection{Chemicals}

Methanol (99.9\% purity, CAS No. 67-56-1) and acetic acid (99.9\% purity, CAS No. 64-19-7) were purchased from Merck (Darmstadt, Germany) and used without further purification. Standard polyphenols: rosmarinic acid (CAS No. 20283-92-5), caftaric acid (CAS No. 67879-58-7), gentisic acid (CAS No. 4955-90-2), chlorogenic acid (CAS No. 32797-9), caffeic acid (CAS No. 331-39-5), p-coumaric acid (CAS No. 501-98-4), ferulic acid (CAS No. 537-98-4), sinapic acid (CAS No. 530-59-6), hyperoside (CAS No. 482-36-0), isoquercitrin (CAS No. 482-35-9), rutin (CAS No. 153-18-4), myricetin (CAS No. 529-44-2), fisetin (CAS No. 345909-34-4), quercitrin (CAS No. 522-12-3), quercetol (CAS No. 117-39-5), luteolin (CAS No. 491-70-3), kaempferol (CAS No. 520-18-3) and apigenin (CAS No. 52036-5) were purchased from Sigma-Aldrich (Germany). Folin-Ciocâlteu reagent (FC), gallic acid (GA, CAS No. 149-91-7), 2,2-diphenyl-1-picrylhydrazyl (DPPH, CAS No. 1898-86-4), ascorbic acid (AA, CAS No. 50-81-7), indometacin (CAS No. 53-86-1) and sodium dodecyl sulfate (SDS, CAS No. 151-21-3) were purchased from Sigma-Aldrich (Steinheim, Germany). Sodium carbonate anhydrous (CAS No. 497-19-8) was obtained from VWR International bvba (Leuven, Belgium). All used reagents were of analytical grade.

\subsection{Cell Culture}

The immortalized human keratinocytes (HaCaT cells) were kindly provided by the University of Debrecen, Hungary. The cells were cultured in high glucose Dulbecco's Modified Eagle's Medium (DMEM; Sigma-Aldrich, Taufkirchen, Germany) supplemented with antibiotic mixture to avoid contamination (Penicillin/Streptomycin 10,000 IU/mL; Sigma-Aldrich, Taufkirchen, Germany) and fetal bovine serum 10\% (FCS; Sigma-Aldrich, Taufkirchen, Germany). The cells were kept in standard conditions-5\% $\mathrm{CO}_{2}$, at a temperature of $37^{\circ} \mathrm{C}$.

\subsection{Total Phenolic Content Determination}

Total phenolic content (TPC) from Artemisia extracts was assessed using Folin-Ciocâlteu reagent [30-32] using an adapted method. The samples, represented by the diluted solutions of the dried extracts $(1000 \mu \mathrm{g} / \mathrm{mL})$, were pipetted into test tubes containing previously diluted (1:10) Folin Ciocâlteu's phenol reagent and, after 5 min at room temperature, sodium carbonate solution $\left(\mathrm{Na}_{2} \mathrm{CO}_{3} 75 \mathrm{~g} / \mathrm{L}\right)$ was added. The mixture was vortexed for $15 \mathrm{~s}$ and then left to stand at room temperature for $2 \mathrm{~h}$ in the dark. Absorbance was measured at $760 \mathrm{~nm}$ using a UV-VIS spectrophotometer (T80+, PG Instruments Ltd., Lutterworth, UK). The calibration curve was established using gallic acid (0-200 $\mu \mathrm{g} / \mathrm{mL})$. Estimation of the 
phenolic content was carried out in triplicate. Total phenolic content was expressed as $\mathrm{mg}$ of gallic acid equivalents (GAE)/g of dry extract (d.e.).

\subsection{Antioxidant Activity In Vitro}

The evaluation of the antioxidant potential of the Artemisia extracts (AAn, AAb, ADr) was performed by the DPPH method [31,33,34], with slight modifications.

The assay is based on the DPPH reduction by the hydrogen donating antioxidants, leading to the discoloration and, subsequently, to the decrease of solution absorbance. Various concentrations $(50-1000 \mu \mathrm{g} / \mathrm{mL})$ of the Artemisia extracts or the pure ascorbic acid (AA) as control, in volumes of $0.2 \mathrm{~mL}$, were added to $1.8 \mathrm{~mL}$ of freshly prepared $0.1 \mathrm{mM}$ DPPH in ethanol. The mixture was incubated in the dark for $30 \mathrm{~min}$, at room temperature. Absorbance was measured against blank samples, at $517 \mathrm{~nm}$, using an UVVIS spectrophotometer (T80+, PG Instruments Ltd., Lutterworth, UK). The decrease in the registered absorbance indicates a free radical scavenging activity. The antioxidant activity (AOA) was calculated as the scavenging capacity of free DPPH radical (in percentages) using the formula:

$$
\operatorname{AOA}(\%)=\left[\frac{A_{0}-A_{s}}{A_{0}}\right] \times 100
$$

where: $A_{0}=$ absorbance of the blank sample and $A_{s}=$ absorbance of the tested samples.

\subsection{LC-MS}

All vegetal extracts were analyzed by an LC-MS analytical method that enables the simultaneous screening and quantification of 18 polyphenols (rosmarinic acid, caftaric acid, gentisic acid, chlorogenic acid, caffeic acid, p-coumaric acid, ferulic acid and sinapic acid, hyperoside, isoquercitrin, rutin, myricetin, fisetin, quercitrin, quercetol, luteolin, kaempferol and apigenin), separated on a reverse phase Zorbax Eclipse Plus C18 column $(3.0 \times 100 \mathrm{~mm} \times 3.5 \mu)$ as previously described [35,36]. Briefly, the mobile phase consisted in a mixture of $0.1 \%$ acetic acid and methanol in gradient elution. The LC-MS parameters were the following: flow rate $1 \mathrm{~mL} / \mathrm{min}$, injection volume $10 \mu \mathrm{L}$, column temperature $40^{\circ} \mathrm{C}$, UV detection at 330 and $370 \mathrm{~nm}$; the elution of all components was achieved in about $40 \mathrm{~min}$. MS detection was achieved by electrospray ionization (ESI) in the single ion monitoring mode (SIM) in the negative ion mode, at the following parameters: capillary voltage $3500 \mathrm{~V}$, dry gas flow $12 \mathrm{~L} / \mathrm{min}$ at $350{ }^{\circ} \mathrm{C}$, nebulizer pressure $55 \mathrm{psig}$ and fragmentor 70 . Calibration curves were conducted for the quantification of polyphenols by the external standard method in the $0.05-2 \mu \mathrm{g} / \mathrm{mL}$ range for a six-point plot for each compound. The $\mathrm{m} / \mathrm{z}$ scale of the mass spectrum was calibrated by use of an external calibration standard ESI Tuning Mix from Agilent (Santa Clara, CA, USA).

HPLC/LC-MS experiments were conducted on a 6120 LC-MS analytical system from Agilent (Santa Clara, CA, USA) consisting of 1260 Infinity HPLC equipped with G1322A degasser, G1311B quaternary pump, G1316A column thermostat, G1365C MWD detector and G7129A autosampler; the Quadrupolar $(\mathrm{Q})$ mass spectrometer is equipped with an electrospray ionization source (ESI). The LC-MS system is controlled by OpenLAB CDS ChemStation Workstation software.

Sample solutions were diluted with methanol, homogenized with a WisdVM-10 vortex mixer (Witeg Labortechnik, Wertheim, Germany) and centrifuged for 2 min at 10,000 rpm in a ThermoMicro CL17microcentrifuge (Thermo Fisher Scientific, Boston, MA, USA). The supernatant was collected and submitted to LC-MS analysis.

\subsection{Cell Viability Assessment by Alamar Blue Assay}

The technique was performed in order to establish cells viability following stimulation with various concentrations of the extracts. The principle of the technique consists in the ability of viable cells to reduce resazurin to the fluorescent form, resorufin. The assay was performed as previously described by Cosarca et al. [37]. Briefly, $1 \times 10^{4}$ cells/well were 
cultured in 96-well plates and allowed to adhere. The second day, the cells were stimulated with different concentrations of the extracts $(10,25,50,100,250,500,750$ and $1000 \mu \mathrm{g} / \mathrm{mL})$ for a period of $72 \mathrm{~h}$. After the $72 \mathrm{~h}$ stimulation, $20 \mu \mathrm{L} /$ well of Alamar blue $(10 \%$ of the volume of cell culture medium) was added and the cells were further incubated at $37^{\circ} \mathrm{C}$ for $3 \mathrm{~h}$. Then, the absorbance was measured at 570 and $600 \mathrm{~nm}$ using the xMark Microplate spectrophotometer (BioRad, xMark ${ }^{\mathrm{TM}}$ Microplate, Serial No. 10578, Tokyo, Japan).

\subsection{Cell Cytotoxicity Assessment by LDH Assay}

Lactate dehydrogenase (LDH) assay (CyQUANT, Thermo Fisher Scientific, Boston, MA, USA) was performed to determine the cytotoxic effect of the Artemisia extracts on HaCaT cells. Different concentrations were used, namely 10, 25, 50, and $100 \mu \mathrm{g} / \mathrm{mL}$. The assay was performed as previously described by Ghitu et al. [38]. For the experiment, $5 \times 10^{3}$ cells / well were cultured in 96-well culture plates and left to adhere. On the second day, the cells were stimulated with the above-mentioned concentrations and incubated for $72 \mathrm{~h}$. After the 72-h stimulation, a volume of $50 \mu \mathrm{L}$ was transferred from each well into a new 96-well culture plate, mixed with $50 \mu \mathrm{L} /$ well of the reaction mixture and further incubated at room temperature for $30 \mathrm{~min}$. Then, $50 \mu \mathrm{L}$ of stop solution was added to each well. The level of LDH release in the medium was determined at two wavelengths (490 and $680 \mathrm{~nm}$ ) using the xMark Microplate spectrophotometer (BioRad, xMark ${ }^{\mathrm{TM}}$ Microplate, Serial No. 10578, Tokyo, Japan).

\subsection{Wound Healing Technique by Scratch Assay}

The method called "wound healing assay" is the most common in vitro assay for cell migration ability, useful for describing the ability of keratinocytes to migrate and to restore the epidermal barrier affected by injury, a first step in the healing process. The assay was performed as previously described $[19,39]$. The migration capacity of HaCaT cells following stimulation with $100 \mu \mathrm{g} / \mathrm{mL}$ of each Artemisia extract was evaluated. In brief, $2 \times 10^{5}$ cells/well were cultured in 12-well plates and allowed to adhere. When a $90 \%$ confluence was reached, we used a sterile pipette tip in order to draw scratches in the center of the wells. Cells that detached following the procedure were removed by washing with phosphate-buffered saline (PBS) before stimulation. Then, the cells were stimulated with the extractive solutions $(100 \mu \mathrm{g} / \mathrm{mL})$. Pictures of the cells were taken at 0 and $24 \mathrm{~h}$ post-stimulation using an inverted microscope (Olympus IX73) provided with DP74 camera (Olympus, Tokyo, Japan). Image analysis for cell migration was performed by means of ImageJ (ImageJ Version 1.53k, https: / / imagej.nih.gov/ij/index.html, accessed on 4 November 2021) and GIMP software (GIMP v 2.10.24, https:/ / www.gimp.org/, accessed on 6 January 2022).

The wound closure rate was calculated using the formula described by Felice et al. [40]:

$$
\text { Wound closure rate }(\%)=\left[\frac{A_{t 0}-A_{t}}{A_{t 0}}\right] \times 100
$$

where: $A_{t 0}$ is the scratch area at time $0 ; A_{t}$ is the scratch area at $24 \mathrm{~h}$.

\subsection{The Chorioallantoic Membrane Assay}

The evaluation of the active potential of Artemisia sp. was also performed in vivo, in order to assess the modulatory effect on angiogenesis with an important role in tissue healing and toxicity [40]. The in ovo chorioallantoic membrane (CAM) assay was performed. The fertilized chicken (Gallus gallus domesticus) eggs were incubated in controlled humidified atmosphere at $37^{\circ} \mathrm{C}$. On the third day of incubation, 4-5 mL of egg white were removed so that the developing chorioallantoic membrane could detach from the inner shell. The following day, a window was cut on the upper shells and resealed to avoid dehydration; the incubation continued until the experimental process [41,42].

To investigate the potential influence on the angiogenesis process of Artemisia extracts, samples were prepared in concentrations of $100 \mu \mathrm{g} / \mathrm{mL}$ in $0.5 \%$ DMSO and volumes of 
$5 \mu \mathrm{L}$ were applied inside plastic rings previously placed on CAMs on the 8th day of incubation. All tested specimens were daily monitored by stereomicroscopy (ZEISS SteREO Discovery.V8, Göttingen, Germany). Images were registered and processed by Axiocam 105 color, AxioVision SE64. Rel. 4.9.1 Software, (ZEISS Göttingen, Germany), ImageJ (ImageJ Version 1.53k, https:/ /imagej.nih.gov/ij/index.html, accessed on 4 November 2021) and GIMP software (GIMP v 2.10.24, https:/ / www.gimp.org/, accessed on 6 January 2022).

\subsection{The Anti-Irritant Effect In Ovo by the HET CAM Method}

Using the same biological material as for the angiogenic evaluation, the anti-irritant effect of the Artemisia extracts was assessed by applying a modified protocol of the HETCAM test (hen egg test chorioallantoic membrane assay), which is known as an alternative protocol for evaluating the potential irritative effect of compounds intended for ophthalmic and dermatologic products, or as a method of assessing in vivo biocompatibility [43-45]. The protocol used here was an adapted alternative to the HET-CAM method as recommended by ICCVAM [46]. The anti-irritative approach was used after Wilson et al. [47] to assess the potential beneficial preventive effects of the extracts when in contact with an irritant agent.

The fertilized eggs prepared as described above were incubated until the 9th day of incubation.At this point, by stereomicroscope assistance, $0.3 \mathrm{~mL}$ of the control or test samples were applied to the membrane; then, after $20 \mathrm{~min}$, the irritating solution of sodium dodecyl sulfate (SDS) was applied $(0.5 \%)$. The tested membranes were monitored over a period of $300 \mathrm{~s}$, by means of a stereomicroscope; the time for the occurrence of the selected parameters (hemorrhage, $\mathrm{H}$; vascular lysis, L; coagulation, C) was recorded in seconds. The irritation score (IS) was then calculated using the followig equation:

$$
\text { IS }=5 \times\left[\frac{301-\operatorname{Sec} H}{300}\right]+7 \times\left[\frac{301-\operatorname{Sec} \mathrm{L}}{300}\right]+9 \times\left[\frac{301-\operatorname{Sec} \mathrm{C}}{300}\right]
$$

where, hemmorrhage $(\mathrm{Sec} \mathrm{H})=$ start of observation (in seconds) of bleeding reactions on the membrane, lysis time (Sec L) = start of observation (in seconds) of lysis of the vessel on the membrane, coagulation time (Sec L) = start of observation (in seconds) of the formation of coagulation on the membrane.

The positive control was considered treatment only with sodium dodecyl sulfate (SDS), while the negative control was treatment with just distilled water. DMSO in a concentration of $0.5 \%$ was also tested as solvent control; indometacin represented the anti-inflammatory control.

\subsection{Statistical Analysis}

Statistical analysis was performed with GraphPad Prism 5 software (San Diego, CA, USA). For the in vitro results; comparison among the groups was performed using the one-way ANOVA followed by Dunnett's multiple comparison test $\left({ }^{*} p<0.05\right.$; ${ }^{* *} p<0.01$; $\left.{ }_{* * *} p<0.001\right)$. Data were represented as Mean \pm SD.

\section{Results}

\subsection{Total Polyphenolic Content}

The obtained experimental data allowed the calculation of the equation resulted from the standard curve, $y=0.009 x+0.1865, R^{2}=0.9798$.

The total phenolic content, expressed in mg GAE/g dry extract, as indicated in Table 1, reached the highest value of $193.61 \pm 2.36$ the case of AAb extract. The value of the total phenolic content for the AAn and ADr extract had lower values of 129.28 \pm 2.09 and $144.28 \pm 1.87$, respectively. 
Table 1. Total phenolic content of Artemisia extracts.

\begin{tabular}{cc}
\hline Extract & $\begin{array}{c}\text { Total Phenolic Content } \\
\text { mg GAE/g Dry Extract }\end{array}$ \\
\hline AAn & $129.28 \pm 2.09$ \\
ADr & $144.28 \pm 1.87$ \\
AAb & $193.61 \pm 2.36$ \\
\hline
\end{tabular}

\subsection{Good Radical Scavenging Activity of Artemisia Species}

The antioxidant activity of the samples was evaluated using the DPPH assay.

In Figure 1 is shown the AOA\% (antioxidant activity \%) of the studied extracts next to the standard compound, ascorbic acid $50 \mu \mathrm{g} / \mathrm{mL}$. It can be observed that the antioxidant activity is directly proportional to the concentration of the extracts.
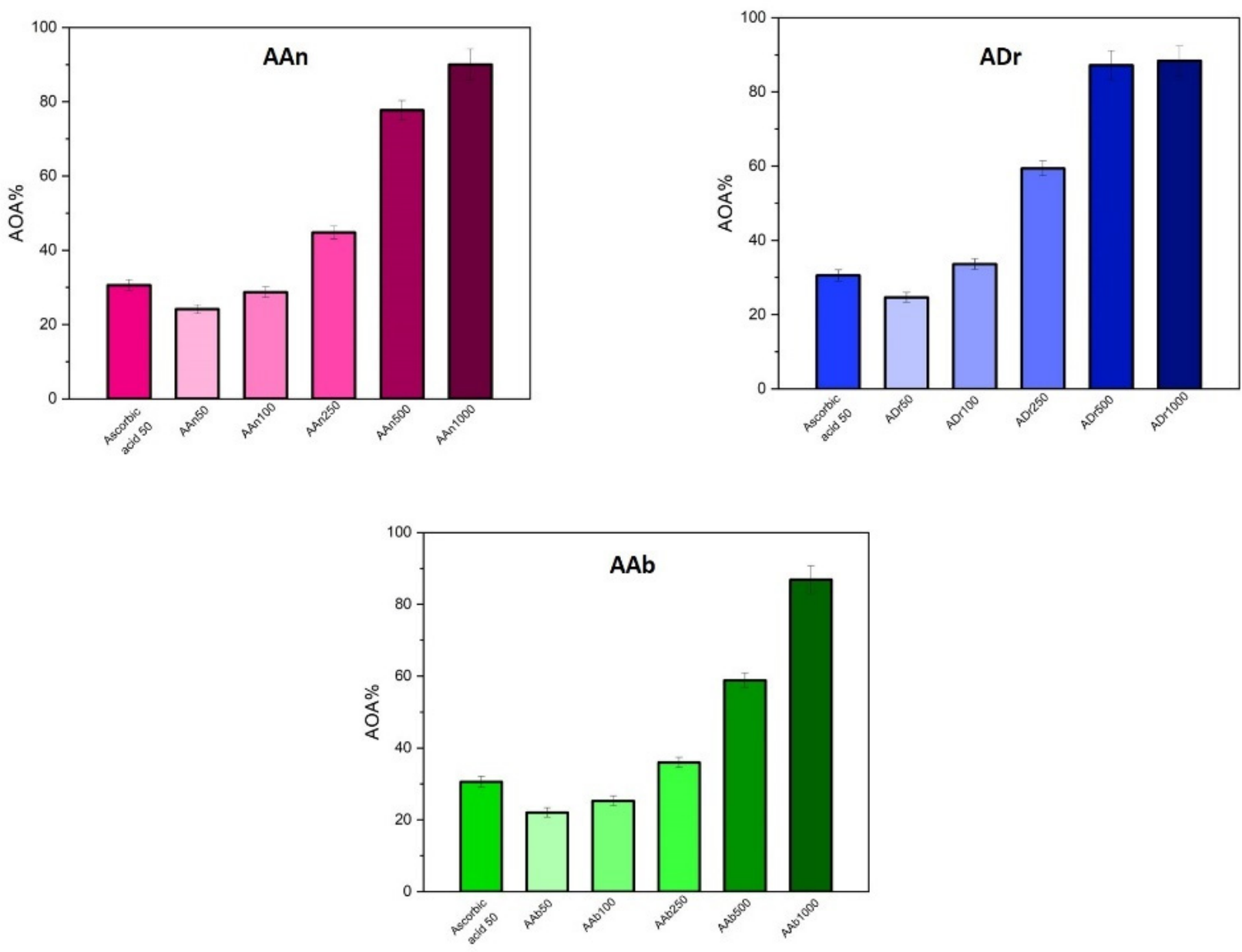

Figure 1. Antioxidant activity of the AAn, ADr and AAb extracts.

Artemisiae annue herba-AAn induced an antioxidant activity of $24.14 \pm 0.6 \%$ for the lowest tested concentration AAn at $50 \mu \mathrm{g} / \mathrm{mL}$ and goes up to $90.04 \pm 2.25 \%$ for AAn at $1000 \mu \mathrm{g} / \mathrm{mL}$. The AOA\% values for the AAn extracts show a comparable antioxidant activity with the one of the standard-ascorbic acid, starting with AAn $100 \mu \mathrm{g} / \mathrm{mL}$. At higher concentrations, 250,500 and $1000 \mu \mathrm{g} / \mathrm{mL}$ a much intense AOA as compared to the standard antioxidant can be observed.

The antioxidant activity of $A$. dracunculus ranged from $24.66 \pm 0.63 \%$ (concentration $50 \mu \mathrm{g} / \mathrm{mL}$ ) to $88.37 \pm 2.25 \%$ (concentration of $1000 \mu \mathrm{g} / \mathrm{mL}$ ). In addition, we determined in this study the $\mathrm{AOA} \%$ for the $A$. absinthium extract and the values started at $22.03 \pm 0.52 \%$ 
for the lowest concentration of $50 \mu \mathrm{g} / \mathrm{mL}$ and increased to $86.87 \pm 2.15 \%$ for the highest concentration of the extract.

All three tested extracts induced an important antioxidant effect, above $100 \mu \mathrm{g} / \mathrm{mL}$, comparable to the effect of $50 \mu \mathrm{g} / \mathrm{mL}$ AA. At this particular concentration, of $100 \mu \mathrm{g} / \mathrm{mL}$, A. dracunculus had a higher antioxidant capacity $(33.65 \pm 1.98 \%)$ than the standard AA $(30.57 \pm 1.02 \%)$.

Although the antioxidant capacity of the three Artemisia species showed similar effects, by comparing the values obtained for concentrations of $1000 \mu \mathrm{g} / \mathrm{mL}$, the AOA capacity fall in the following order: AAn > ADr > AAb. Still, interestingly, above the concentration of $100 \mu \mathrm{g} / \mathrm{mL}$ up to $1000 \mu \mathrm{g} / \mathrm{mL}$, the most potent extract is the one obtained from tarragon $(\mathrm{ADr})$.

\subsection{Polyphenols and Phenolic Acids in Artemisia Species}

LC-MS analysis of sample extracts of Artemisia dracunculus L. (ADr), Artemisia annua L. (AAn) and Artemisia absinthium L. (AAb) were conducted under identical solution and instrumental conditions. The obtained results revealed the identification and in some cases quantification, according to their $R_{\mathrm{t}}$ and $\mathrm{m} / \mathrm{z}$ values, of a total of 11 polyphenols in all analyzed extracts combined with some differences in terms of their expression in each extract (Table 2). Identified polyphenols fall into polyphenolic acids group, cinnamic acid derivatives, and flavonoids, flavones and flavonols respectively. Identified phytocompounds were gentisic acid, chlorogenic acid, caffeic acid, ferulic acid, isoquercitrin, rutin, quercitrin, quercetol, luteolin, kaempferol and apigenin, expressed as $\mu \mathrm{g} / \mathrm{mg}$ d.e. The most important polyphenols identified in all extracts, consistent with their concentration, were chlorogenic acid, rutin and quercetol, the most abundant one being chlorogenic acid. Meanwhile, gentisic acid, caffeic acid, ferulic acid, isoquercitrin, quercitrin, luteolin, and apigenin were identified in smaller concentrations, or even in traces, falling below the limit of quantification in some cases. Some differences regarding the expression of polyphenols in the three types of extracts were spotted out, such as quercitrin and isoquercitrin, identified in AAb and AAn extract, but not in ADr extract, concurrently, kaempferol, which was found only in ADr extract, in a substantial amount. The expression of the dominant compound, chlorogenic acid respectively, was almost equivalent in AAn and ADr extracts, while $\mathrm{AAb}$ exhibited a concentration almost four times lower. The richest extract consistent with the concentration of identified compounds was ADr, while AAb contained the lowest amounts.

Table 2. Identified polyphenols by LC-MS.

\begin{tabular}{|c|c|c|c|c|c|c|}
\hline No. & Compound Name & $\underset{(\mathrm{min})}{R_{\mathrm{t}}}$ & $\begin{array}{c}{\left[\mathbf{M}-\mathbf{H}^{+}\right]^{+}} \\
(m / z)\end{array}$ & $\begin{array}{c}\text { AAn } \\
\text { ( } \mu \text { g/g d.e.) }\end{array}$ & $\begin{array}{c}\text { AAb } \\
(\mu \mathrm{g} / \mathrm{g} \text { d.e. })\end{array}$ & $\begin{array}{c}\text { ADr } \\
\text { ( } \mu \text { g/g d.e. })\end{array}$ \\
\hline 1. & Gentisic acid & 2.67 & 153 & ND & NQ & NQ \\
\hline 2. & Chlorogenic acid & 6.45 & 353 & 12.4 & 3.15 & 11.77 \\
\hline 3. & Caffeic acid & 6.97 & 179 & 0.06 & 0.009 & NQ \\
\hline 4. & Ferulic acid & 13.91 & 193 & ND & ND & $\mathrm{NQ}$ \\
\hline 5. & Isoquercitrin & 22.50 & 463 & 0.5 & 0.15 & $\mathrm{ND}$ \\
\hline 6. & Rutin & 23.01 & 609 & 0.4 & 0.33 & 2.87 \\
\hline 7. & Quercitrin & 26.18 & 447 & 0.9 & 0.73 & ND \\
\hline 8. & Quercetol & 30.38 & 301 & 0.11 & 0.07 & 5.54 \\
\hline 9. & Luteolin & 32.78 & 285 & NQ & NQ & ND \\
\hline 10. & Kaempferol & 35.63 & 285 & $\widehat{N D}$ & $\widehat{N D}$ & 4.44 \\
\hline 11. & Apigenin & 36.91 & 269 & NQ & NQ & NQ \\
\hline
\end{tabular}

Notes: ND—not detected, below the limit of detection; NQ—not quantified, below the limit of quantification.

\subsection{Human Keratinocyte Viability and Cytotoxicity}

The effect of the Artemisia extracts-Artemisia annua L. (AAn) Artemisia absinthium $\mathrm{L}$ (AAb), Artemisia dracunculus L. (ADr), was evaluated on HaCaT keratinocytes after a stimulation period of $72 \mathrm{~h}$ (Figure 2). The Control group is represented by cells treated with 
the solvent dimethyl sulfoxide (the DMSO concentration did not exceed $0.5 \%$ ). In Figure $2 \mathrm{a}$, it can be observed that AAn, at concentrations ranging from 10 to $250 \mu \mathrm{g} / \mathrm{mL}$, produced a significant increase in cells viability. Only at higher concentrations, $500-1000 \mu \mathrm{g} / \mathrm{mL}$, was a decrease in cells viability noticed. A similar effect was obtained for AAb (Figure $2 b$ ) and ADr extracts (Figure 2c).
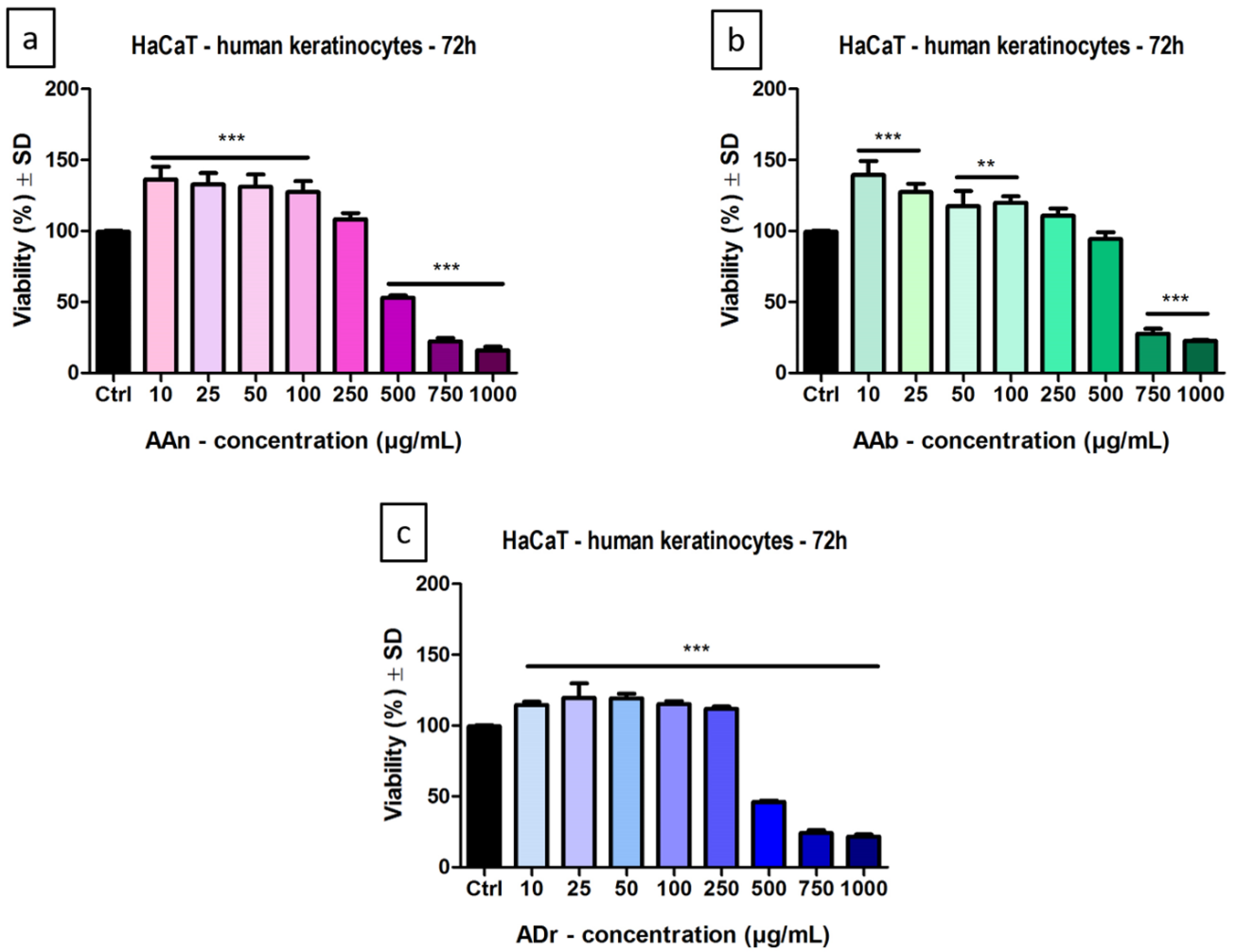

Figure 2. HaCaT cells viability $72 \mathrm{~h}$ after stimulation with the extracts ( $-\mathrm{AAn}, \mathrm{b}-\mathrm{AAb}, \mathrm{c}-\mathrm{ADr}$ ) at different concentrations $(10,25,50,100,250,500,750$ and $1000 \mu \mathrm{g} / \mathrm{mL})$. Data are expressed as mean \pm SD. One-way ANOVA and Dunnett's multiple comparison post-test were used for comparison among groups $\left({ }^{* *} p<0.01,{ }^{* * *} p<0.001\right.$ vs. Control).

The highest increase in keratinocytes viability was induced by the sweet wormwood, followed by the wormwood extract and last by the tarragon extract (AAn > AAb > ADr). In terms of decreasing the cells viability, the most significant reduction was obtained at the highest concentration, $1000 \mu \mathrm{g} / \mathrm{mL}$, for AAn—cells viability was $15.8 \pm 2.6 \%$ vs. Control; for AAb-cells viability was $22.6 \pm 0.4 \%$ vs. Control; for ADr-cells viability was $21.6 \pm 1.4 \%$ vs. Control.

Figure 3 depicts the effect of the Artemisia extracts on $\mathrm{LDH}$ release. At the tested concentrations, for all samples, no cytotoxic effect was observed compared to Control. Moreover, a decrease in LDH release was obtained following stimulation with the extracts. We determined the cytotoxic effect at these concentrations by analyzing the viability assay results, where an increase in cells viability was obtained and we intended to add a proof that the human keratinocytes were not affected by these extracts.

\subsection{Wound-Healing Effect In Vitro on Human Keratinocyte}

This experimental model was performed using healthy keratinocyte cells, in order to explore the ability of the three Artemisia extracts to stimulate cells migration, a process that can be considered a first phase of lesion regeneration and can be correlated with wound closure, thus with the reduction of the open and vulnerable surface. 

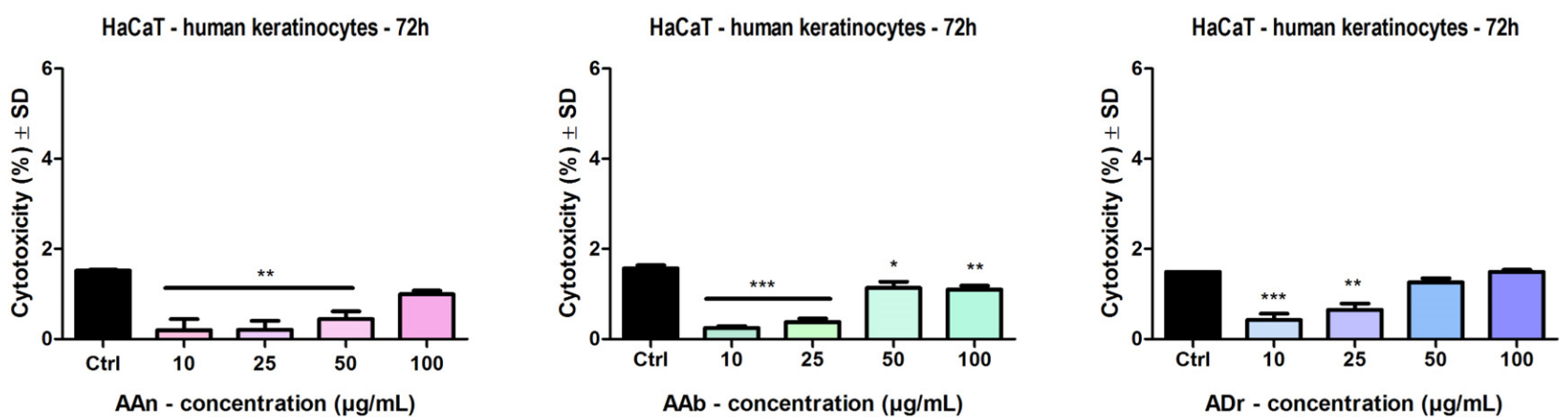

Figure 3. The cytotoxic effect of the extracts (AAn, AAb, ADr) at different concentrations (10, 25, 50 , and $100 \mu \mathrm{g} / \mathrm{mL}$ ). Data are expressed as mean $\pm \mathrm{SD}$. One-way ANOVA and Dunnett's multiple comparison post-test were used for comparison among groups $\left({ }^{*} p<0.05,{ }^{* *} p<0.01,{ }^{* * *} p<0.001\right.$ vs. Control).

Representative images of HaCaT cells are presented in Figure 4. The Control group is represented by cells treated with the culture medium, while the DMSO group represents cells treated with the solvent dimethyl sulfoxide. As shown in Figure 4, AAn and AAb extracts produced, at $100 \mu \mathrm{g} / \mathrm{mL}$, almost a complete restoration of the scratch area, with wound closure rates of $98.55 \pm 0.64 \%$ and $97.84 \pm 1.98 \%$, respectively, thus, indicating that the samples stimulated keratinocytes migration and wound closure. The ADr extract, at $100 \mu \mathrm{g} / \mathrm{mL}$, increased cell migration with a wound closure rate of $89.65 \pm 2.18 \%$. The scratch closure percentage was lowest for the solvent used, DMSO (71.13 $\pm 5.69 \%)$.
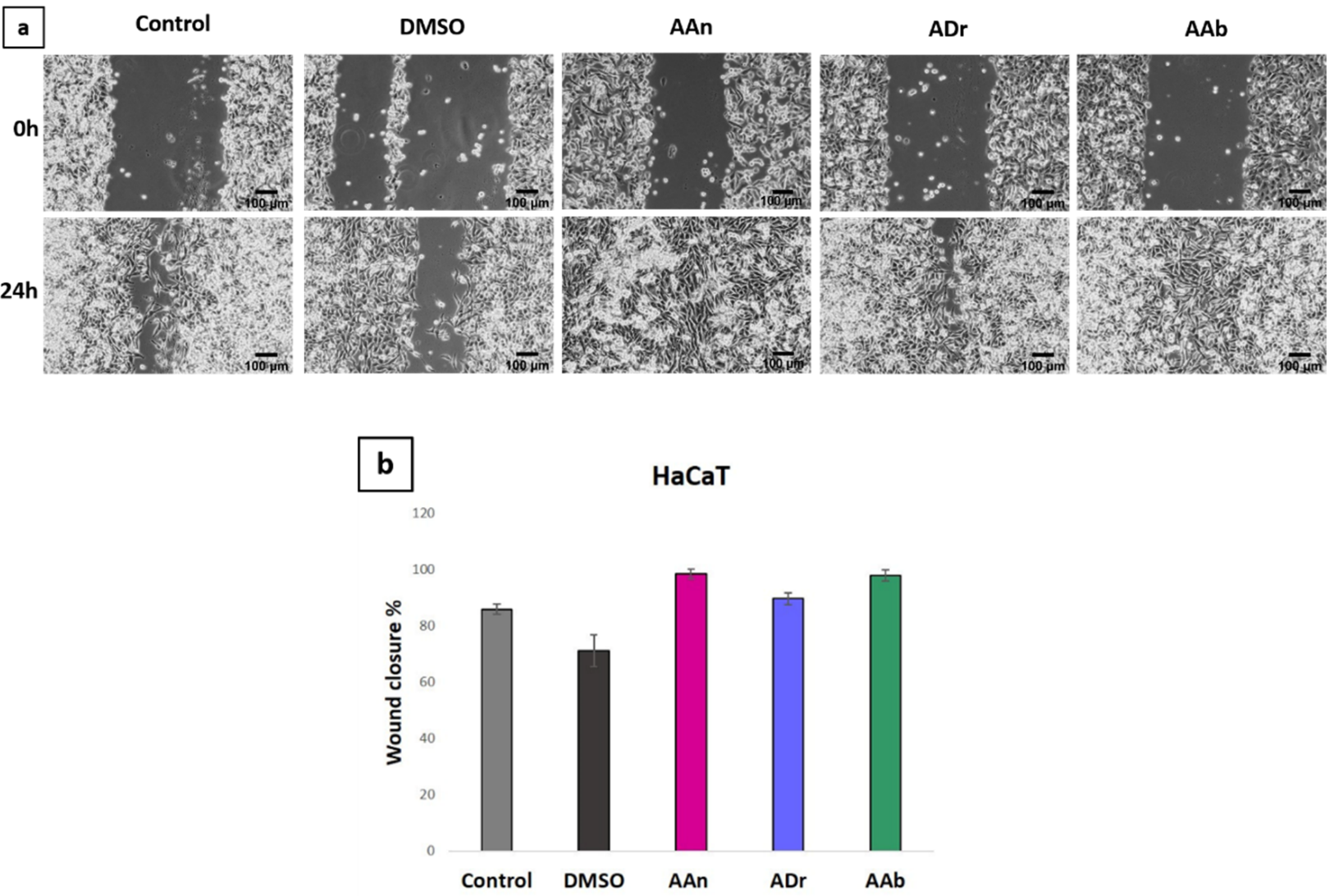

Figure 4. (a) Microscopic images representing the HaCaT cells treated with the three extracts of Artemisia species $(100 \mu \mathrm{g} / \mathrm{mL})$, initially at $0 \mathrm{~h}$ and at $24 \mathrm{~h}$, respectively, visualized by light microscopy at $10 \times$ magnification; (b) Results were expressed as wound closure percentage after $24 \mathrm{~h}$ compared to the initial scratch length. Mean values \pm SD of three independent experiments $(n=3)$. 


\subsection{Angiogenesis Modulation on CAM Assay}

For the in vivo evaluation of the potential influence upon the wound healing process, we selected the $100 \mu \mathrm{g} / \mathrm{mL}$ concentration for the three Artemisia extract solutions, based on the fact that, at this concentration, the antioxidant effect was significant; when tested on the $\mathrm{HaCaT}$ cell viability, at this concentration, there was an increase in the viability of the cells, compared to higher concentrations that induced a reduction in cell viability.

The samples were assessed by evaluating the effect on the physiologic angiogenic process, starting with the 8 th day of incubation. The rapid growth of the vessels took place from day 7 up to day 11 of incubation [48].

The effect was evaluated $24 \mathrm{~h}$ and $72 \mathrm{~h}$ after treatment, as represented in Figure 5. After one dose at $24 \mathrm{~h}$ post treatment, no relevant modifications were observed concerning the normal developing vessel architecture. Visible changes were noted after 3 doses at $72 \mathrm{~h}$ after treatment; different effects were observed for the three Artemisia extracts. An increase in the number of small vessels was induced by the AAn extracts, while the ADr also increased the number of bigger vessels inside the ring with a spokes-wheel pattern, compared to the control specimens. The vascular network was less affected by the AAb at $100 \mu \mathrm{g} / \mathrm{mL}$ concentration, inducing after $72 \mathrm{~h}$ post-treatment a lower increase in vessel growth; still, a significant number of small new forming capillary branches, derived from main vessels, were present.
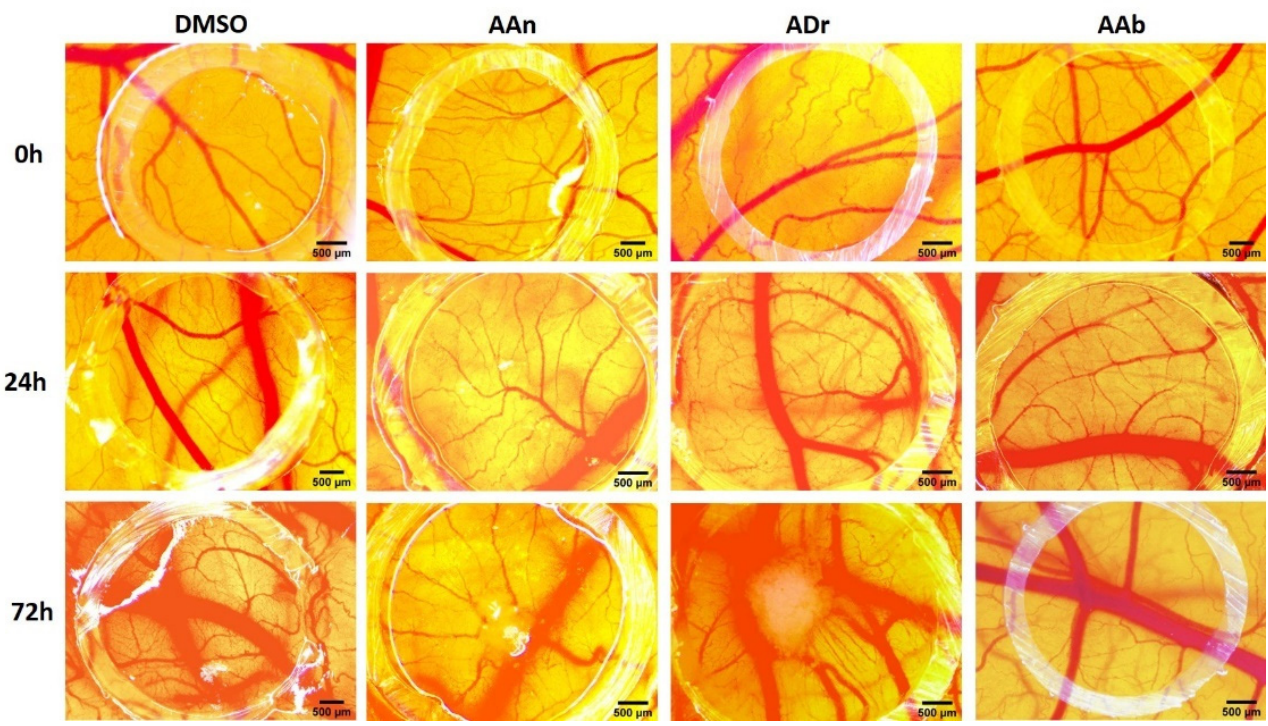

Figure 5. Stereomicroscopic images showing the effects produced by the Artemisia extracts on the CAM; images are represented initially at $0 \mathrm{~h}, 24 \mathrm{~h}$ and $72 \mathrm{~h}$ post-treatment, for the solvent control DMSO and the three Artemisia extracts; scale bars represent $500 \mu \mathrm{m}$.

With potential pro-angiogenesis effects at the tested concentration, extracts of sweet wormwood and tarragon may be especially beneficial in the vascular phase of wound healing. All the solutions showed good tolerability, with no influence upon embryo viability.

\subsection{Anti-Irritant Effect Evaluated Using the HET-CAM Assay}

Using a modified version of the HET-CAM protocol for the irritant effect, we assessed here the ability of the tested extracts to exert preventive and anti-irritative effects upon exposure to the irritant agent sodium dodecyl sulfate (SDS 0.5\%). As shown in Figure 6, the results obtained after stereomicroscopic monitoring for $5 \mathrm{~min}$ reflected the degree of irritation reduction compared to the sample treated only with SDS. The study also included, as anti-inflammatory control, indometacin. 

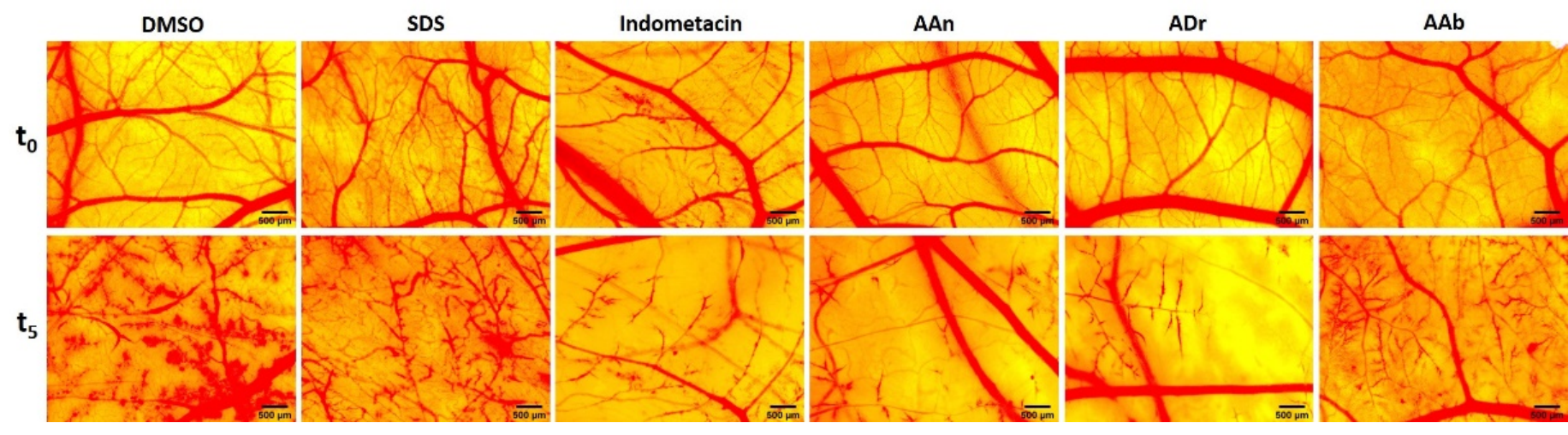

Figure 6. Stereomicroscopic images showing the effects induced by the Artemisia extracts on the CAM using the anti-irritative HET-CAM assay; images represent the initial moment, before application of the irritant SDS $0.5 \%\left(t_{0}\right)$, and $5 \mathrm{~min}$ after application of the irritant $\left(t_{5}\right)$; DMSO represents the solvent control and indometacin, the anti-inflammatory control; scale bars represent $500 \mu \mathrm{m}$.

Comparing the irritative scores (Table 3) of the plant extracts at the concentration of $100 \mu \mathrm{g} / \mathrm{mL}$ with the score obtained by SDS alone, it is noticeable that a reduction of the IS was registered for all three extracts. The IS values calculated for the Artemisia extracts were also reduced compared to the solvent control; yet, the irritation scores were still higher when compared to the anti-inflammatory agent $(I S=16.69)$. According to the irritation scale recommended by Luepke [49], the irritation scores can be classified as following: 0-0.9-non-irritant, 1-4.9 weak irritant, 5-8.9 moderate irritant, 9-21 strong irritant.

Table 3. The irritative scores of the analyzed samples in the anti-irritative HET-CAM assay.

\begin{tabular}{cc}
\hline Samples & Irritative Score \\
\hline AAn & 18.38 \\
ADr & 19.01 \\
AAb & 19.69 \\
DMSO & 20.13 \\
SDS & 20.36 \\
Indometacin & 16.74 \\
\hline
\end{tabular}

Within this experimental setting, for the evaluated concentration of the extracts, a similar anti-irritative effect was noticed for all three extracts, with AAn inducing the strongest effect (IS = 18.38), followed by ADr (IS = 19.01) and AAb (IS = 19.69).

\section{Discussions}

The management of the complicated disruptive wound healing processes is a real challenge that is confronted with limitations of the health systems. Thus, effort is made to identify low costs alternatives, especially of natural origin, efficient activators of the complex process of wound healing. Medicinal plants, with high content of polyphenolic compounds, are an important approach to reduce the high levels of oxidative stress that, in most cases, affects the healing process. Hence, in our study, we focused on the phenolic profile of our extracts, in correlation with their potential antioxidant activities. Likewise, the DPPH radical scavenging activity assay was performed in order to evaluate the antioxidant capacity of the three Artemisia extracts. A great number of natural compounds are also essential as antimicrobial agents, next to stimulating skin cell proliferation, migration or modelling the disruptive vascular process, thus, acting as multiple targeting active agents in the wound microenvironment [50-52].

In the current study, we selected three Artemisia species (A. annua, A dracunculus and A. absinthium) with a background in traditional skin ailment therapy and available on the herbal market of our country [53]. Confirmatory studies of the potential benefits in wound 
healing and regenerative medicine are still lacking; therefore, we intended to contribute with data concerning the phytochemical and bioactive potential of ethanolic extracts of the three Artemisia species.

Based on previous studies [54-56] that showed important content in polyphenolic compounds and lacking potential topical toxicity due to residual solvent remanence after drying, we selected to explore here the content in phenolic compounds of the $80 \%$ ethanolic extracts. The influence of the solvent on the antioxidant potential and chemical composition of Artemisia annua leaves extract was investigated by Iqbal et al. [54]. In terms of TPC, they concluded that the most efficient solvent for the extraction of phenolics from the leaves of AAn are methanol and water, and the less efficient were chloroform and hexane. In the case of the methanolic extract, the TPC was of $134.50 \pm 4.37 \mathrm{mg} / \mathrm{g}$. The extract of Artemisia annuae herba tested in our study contains $129.28 \pm 2.09 \mathrm{mg}$ GAE/g dry extract, using an ethanolic extract and the whole aerial part of the plant.

Kozlowska et al. [55] evaluated the antioxidant potential and the phenolics found in various dried and fresh plants, tarragon (Artemisia dracunculus L.) being one of them. For the extracts preparation the aerial part of the plant and $70 \%(v / v)$ ethanol were used and the TPC was $32.91 \pm 0.68 \mathrm{~g} \mathrm{GAE} / \mathrm{kg}$ extract in case of fresh plant material, while, in the case of dried tarragon, $42.53 \pm 0.93 \mathrm{~g} \mathrm{GAE} / \mathrm{kg}$ extract was obtained. Others obtained TPC values for methanolic tarragon extract in the range $97.2-253.5 \mathrm{mg} \mathrm{GA} / \mathrm{g}$, with a mean value of $151.6 \mathrm{mg} \mathrm{GA} / \mathrm{g}$, while for the water extract the range was 59.5-198.3 $\mathrm{mg} \mathrm{GA} / \mathrm{g}$, and the mean value $102.8 \mathrm{mg}$ GA/g [56]. Therefore, it can be said that the methanolic extract has the closest value to the one obtained by us for the $A$. dracunculus total phenolic content.

The regional area of $A$. absinthium L. collection influenced the total polyphenolic content of the extract, according to Msaada et al. [57]. The maximal value of TPC was $99.89 \pm 3.30 \mathrm{mg}$ GAE/g dried weight, obtained with vegetal material collected from Kairouan region. In the other regions, the TPC (expressed as $\mathrm{mg}$ GAE/g dried weight) had lower values, such as $83.70 \pm 1.31$ in Bou Salem, $72.05 \pm 1.83$ in Boukornine and $49.39 \pm 2.20$ in Jerissa.

A total phenolic content of $194 \pm 9.7 \mathrm{mg}$ gallic acid equivalent/g extract was reported by Ebrahimzadeh et al. [58] for Artemisia absinthium L. The extract was prepared using the aerial parts of the plants collected from Iran and methanol as extracting agent. The value reported for the TPC by Ebrahimzadeh et al. is similar to our results $(193.61 \pm 2.36 \mathrm{mg}$ GAE/g dry extract). In addition, Bora and Sharma presented in their work a value of TPC of $123 \pm 0.82 \mathrm{mg}$ GA equivalents per gram of extract, for A. absinthium (methanolic extract); the extract was made from aerial parts and was procured from Himalaya Herbs Stores, India [59].

Therefore, from all the results presented above it is noticeable that the TPC is influenced by factors like the nature of the extracting agent, the region of the plant collection, the part of the plant used. The highest TPC was obtained for the wormwood extract, followed by the tarragon and then by the sweet wormwood ethanolic extract. The TPC established in our work for the three Artemisia extracts indicates important polyphenolic content of the dry medicinal products available on the market in Romania, being comparable to literature data.

Investigating the free radical scavenging capacity of the three extracts in a concentration range from 50 to $1000 \mu \mathrm{g} / \mathrm{mL}$, our results indicated important antioxidant activities. Extracts in concentrations as high as $100 \mu \mathrm{g} / \mathrm{mL}$ had comparable AOA\% with ascorbic acid $(50 \mu \mathrm{g} / \mathrm{mL})$ used as standard antioxidant agent. For higher concentrations, the antioxidant activities reached values over $90 \%$, in a dose-related manner for all three species. Kim et al. [60] investigated the properties of Artemisia annua L. extracts obtained using different extractants such as water, $80 \%$ methanol, $80 \%$ ethanol and $80 \%$ acetone by the DPPH radical scavenging method. In the study conducted by Kim, the antioxidant activity at a concentration of $0.6 \mathrm{mg} / \mathrm{mL}$ ethanolic extract was $57.0 \pm 1 \%$, slightly lower than $77.71 \pm 1.94 \%$ obtained by us for a concentration of $500 \mu \mathrm{g} / \mathrm{mL}(0.5 \mathrm{mg} / \mathrm{mL})$. 
A. dracunculus leaves and inflorescence in a methanolic extract, used in the work of Khezrilu Bandli and Heidari showed similar DPPH (\%) values for the leaves and inflorescence extracts (86.43 $\pm 0.15 \%$ and $92.03 \pm 0.11 \%$, respectively) [61]. Lower values were obtained for A. absinthium extract prepared from leaves and stems using ethanol $80 \%$ as extractant; for a concentration of $1.4 \mathrm{mg} / \mathrm{mL}$ the leaves extract had $49.47 \pm 0.015 \%$ and the stem extract had $56.84 \pm 0.026 \%$ inhibition [19].

The most numerous studies regarding the three species consider their terpenoid-rich composition; however, their antioxidant effects were moderate. However, the extracts in polar solvents from plant products of the three species of Artemisia have been investigated, regarding the antioxidant effect. Studies have shown that the most concentrated compounds in tarragon are phenolic acids, especially gallic acid, synaptic acid, syringic acid, and the strong antioxidant activity can be accounted for by the high number of hydroxyl groups and the presence of type 2-carboxyl groups [61]. Wormwood is more concentrated in flavonoids next to phenolic acids, and values obtained in other studies indicate an antioxidant potential similar to sweet wormwood or tarragon [62]. Sweet wormwood is studied in most cases due to the presence of the sesquiterpene lactone artemisinin. We observed in the HPLC evaluation (data not shown), that artemisinin was not present in any of our extracts, as previously reported with significant degradability over storage [63]. Thus, the Artemia species tested here, as dried plant material available on the market, are valuable sources of polyphenols and antioxidant products.

The three Artemisia ethanolic extracts are concentrated in phenolic acids, mainly chlorogenic acid, with some differences between species. The highest content in chlorogenic acid was obtained for sweet wormwood, followed by a similar concentration in tarragon, while wormwood was three times less concentrated. As shown by others [64], this may explain the angiogenic activity reported here using the chorioallantoic membrane assay. Chlorogenic acid and flavonoids such as quercetin, kempferol and rutin were also identified in relevant concentrations in the tarragon extract only. A. annua polyphenolic profile was thoroughly investigated by Yi Song et al., who analyzed extracts from flowers, leaves, stems and roots by LC/MS/MS that revealed a rich polyphenolic content, out of which the most abundant compounds were caffeic acid derivatives [65]. Consistent with our findings, the group of Mumivand et al. investigated the polyphenolic content extracted from A. dracunculus, the LC analysis revealing a similar profile as the one identified by our group, phenolic acids out of which chlorogenic acid being the dominant one, accompanied by flavonoids [66]. In a similar approach, the polyphenolic profile of $A$. absinthium extract disclosed a vast phytocompound content, phenolic acids, in particular chlorogenic acid and p-coumaric acid being accountable as major components [57].

Great variability in the phytocompound profile and concentration are distinguished from the available literature data, and significant differences are accounted on the climate, soil, part of the plant, collection variables and extraction protocols. Once again, it reflects the importance of extract standardization worldwide.

The viability of healthy keratinocytes was assessed after exposure to the Artemisia extracts. Exposed to concentration of $100 \mu \mathrm{g} / \mathrm{mL}$ and $250 \mu \mathrm{g} / \mathrm{mL}$ the keratinocyte viability was not hindered, displaying even stimulatory effects in the Alamar blue assay $72 \mathrm{~h}$ following treatment. Wormwood extract at the concentration of $500 \mu \mathrm{g} / \mathrm{mL}$ also did not influence the viability of $\mathrm{HaCaT}$ cells; however, sweet wormwood and tarragon extracts at concentrations of $500 \mu \mathrm{g} / \mathrm{mL}$ and above decreased cells viability; thus, the recommended concentrations for wound healing purposes are up to $250 \mu \mathrm{g} / \mathrm{mL}$. The effects of various Artemisia species were previously reported on different skin cells $[67,68]$. A study conducted on $A$ annua in concentration of $100 \mu \mathrm{g} / \mathrm{mL}$ showed no inhibitory effects on the viability of normal fibroblasts [68]. Oh et al. indicated that Artemisia princeps Pampanini extract did not display a cytotoxic effect on $\mathrm{HaCaT}$ cells at concentrations up to $500 \mu \mathrm{g} / \mathrm{mL}(62.5,125,250$ or $500 \mu \mathrm{g} / \mathrm{mL}$ ) [67]; in addition, Artemisia apiacea showed no cytotoxicity towards HaCaT in concentration up to $200 \mu \mathrm{g} / \mathrm{mL}$ [69]. 
Artemisia absinthium from Serbia [70] was also evaluated and, generally, concentrations below $400 \mu \mathrm{g} / \mathrm{mL}$ showed no cytotoxic effect on keratinocytes, while a Romanian cultivated wormwood extract showed a decrease in HaCaT cells, only at $1000 \mu \mathrm{g} / \mathrm{mL}$ [19]. Another study tested collagen scaffolds containing Romanian A. absinthium extract rich in luteolin and quercetin, and results showed, 5 days following treatment, an improve in fibroblast and keratinocyte proliferation to a higher extent than collagen alone. [71].

Our data regarding the three Artemisia species, AAn, AAb and ADr, indicated no toxicity towards $\mathrm{HaCaT}$ cells at doses up to $250 \mu \mathrm{g} / \mathrm{mL}$. We further investigated the potential cytotoxicity through the LDH assay obtaining a confirmation of the lack of cytotoxicity for the healthy keratinocytes upon treatment with all three Artemisia species up to $100 \mu \mathrm{g} / \mathrm{mL}$.

Interestingly Artemisia capillaris ethanolic extract from Korea, in concentration of $37.5 \mu \mathrm{g} / \mathrm{mL}$ induced an antiproliferative effect on healthy keratinocytes and, thus, considered as a potential anti-psoriatic agent [72].

The in vitro scratch assay exhibited wound closure capacity in healthy human keratinocytes after treatment with $100 \mu \mathrm{g} / \mathrm{mL}$ for all three Artemisia species, indicative for a pro-migratory and proliferative effect of keratinocytes during a wound healing process. Extracts in concentration of $100 \mu \mathrm{g} / \mathrm{mL}$ induced after the drawing of the scratch line, $24 \mathrm{~h}$ following treatment, a cellular density higher than the control. There are fewer studies that investigate in vitro the migratory potential of healthy keratinocytes for Artemisia species. Moaca et al. investigated the migratory potential of Romanian wormwood, and up to $250 \mu \mathrm{g} / \mathrm{mL}$ for the leaves and $500 \mu \mathrm{g} / \mathrm{mL}$ for the stems a pro-migratory effect was reported, while only higher concentrations induced a decrease in the migratory capacity oh $\mathrm{HaCaT}$ cells [19]. A. asiatica in concentrations as low as $5 \mu \mathrm{g} / \mathrm{mL}$ restored the proliferative and migratory potential of keratinocytes after cisplatin induced inhibition [73].

Other studies involving the wound healing potential of Artemisia species use animal models. A. absinthium from Algeria evaluated as an ointment on a rat model improved wound contraction comparable to the control allantoin ointment [74]. A. dracunculus with chitosan nanoparticle biofilm induced significant improvement of wound contraction on rats compared to the other treatment groups [75].

With a high TPC and a potent radical scavenging activity, the effects on the viability and migration potential of healthy keratinocytes of the wormwood extract investigated here, although less concentrated in the phenolic compounds screened in this study, may be related to other phytocompounds such as chalcones, cinnamic acid, artemetin as previously shown by others [74].

The skin wound healing process involves a cascade of complex events including angiogenesis. The angiogenic activity was assessed by the CAM model and a visible increase of new vessel formation was observed $72 \mathrm{~h}$ after treatment with concentrations of $100 \mu \mathrm{g} / \mathrm{mL}$, compared to Control specimens. Slight differences between the three tested extracts were noted, with $A$. dracunculus and A. annua inducing the more pronounced effect. Limited studies investigated the angiogenic potential of the three Artemisia species. Several data indicate the anti-angiogenic effect, but for different species, such as A. sieberi [76], A. capillaris in a polyherbal anti-obesity preparation [77] or A. herba-alba essential oil [78]. Other studies involving $A$. annua, showed that mostly sesquiterpenoid artemisinins are responsible for the anti-angiogenic effect $[79,80]$. However, the pro-angiogenic effect induced in ovo using the CAM assay can be explained based on the dominant phenolic compound in all three extracts, chlorogenic acid, and its hormetic behavior reported as a proangiogenic agent at small concentrations of $10 \mu \mathrm{g} / \mathrm{mL}$, significantly increasing endothelial cell migration and stimulating capillary tube formation $[64,81,82]$.

Finally, using the in ovo chorioallantoic membrane, and a modified HET-CAM protocol, we assessed the anti-irritative potential of the three extracts in concentrations of $100 \mu \mathrm{g} / \mathrm{mL}$. The assay allowed observing the potential preventive and healing capacities of the extracts when exposed to a highly irritant agent, sodium dodecyl sulfate. Although the results did not show a major improvement of the damaged vascular area, limitative 
effects can be underlined as the irritation score obtained for the three extracts indicated a superior effect as compared to the solvent control alone. A. annua and A dracunculus showed a slightly higher anti-irritative effects.

The three Artemisia species available on the herbal market in Romania investigated as $80 \%$ ethanolic extracts displayed a high content in phenolic compounds, with different phytochemical profile following LC-MS analysis. All extracts showed chlorogenic acid as dominant polyphenol; $A$. annua and $A$. dracunculus revealed to be almost three times more concentrated than A. absinthium. Still, accounting for high TPC values; similar biological effects were registered by the three species, in terms of in vitro radical scavenging activity, proliferative and pro-migratory effects on keratinocytes. The angiogenic process was also promoted by all three extracts in concentration of $100 \mu \mathrm{g} / \mathrm{mL}$, with a different, more pronounced impact in the case of $A$. annua and $A$. dracunculus. Moreover, potentially beneficial in alleviating skin irritation, the three Artemisia extracts are safe to use on cutaneous and mucosal tissues.

\section{Conclusions}

We demonstrated the effective promotion of normal keratinocyte proliferation and migration by the three Artemisia extracts. Up to a concentration of $100 \mu \mathrm{g} / \mathrm{mL}$ the extracts enhanced cell viability, restored wound closure and slightly reduced the irritation induced by SDS in ovo. Angiogenesis was activated by increasing new vessel formation, especially by $A$. annua and $A$. dracunculus extracts with significantly higher content of chlorogenic acid. The high total phenolic content and the significant radical scavenging activities of the three Artemisia extracts are important features potentially improving the wound healing dysregulated microenvironment. The three Artemisia species, easily available on the herbal market, may represent low-cost alternatives, benefitting from a multi-targeted mechanism and a safe profile, hence applicable in the design of novel wound dressing preparations for wound care management.

Author Contributions: Conceptualization, R.G., D.M. (Daliana Minda), I.Z.P. and S.A.; extract preparation, D.M. (Daliana Minda); antioxidant activity, D.M. (Daliana Minda), R.R. and D.M. (Delia Muntean); physicochemical screening, Z.D.; R.G., C.D.B. and O.D.B.; in vitro assays, I.Z.P. and O.D.B.; angiogenesis, S.A.; Formal analysis, R.G. and C.D.B.; funding acquisition, I.Z.P.; resources, C.S., C.A.D., I.Z.P. and S.A.; writing-original draft preparation, R.G., C.D.B., I.Z.P., C.D., R.R., Z.D. and S.A.; writing-review and editing, C.S., C.A.D. and S.A.; validation, C.A.D., C.S. and S.A.; visualization, R.G., C.D.B., I.Z.P., R.R. and S.A.; supervision, S.A. All authors have read and agreed to the published version of the manuscript.

Funding: This research was funded by the Project PN-III-P1-1.1-PD-2019-1231, No. PD 206/2020, Project Director Ioana Zinuca Pavel.

Institutional Review Board Statement: Not applicable.

Informed Consent Statement: Not applicable.

Data Availability Statement: The data supporting the findings of the study are available within the article.

Conflicts of Interest: The authors declare no conflict of interest.

\section{References}

1. Pereira, R.F.; Bártolo, P.J. Traditional Therapies for Skin Wound Healing. Adv. Wound Care 2016, 5, 208-229. [CrossRef] [PubMed]

2. Shedoeva, A.; Leavesley, D.; Upton, Z.; Fan, C. Wound Healing and the Use of Medicinal Plants. Evid.-Based Complement. Altern. Med. 2019, 2019, 2684108. [CrossRef] [PubMed]

3. Tottoli, E.M.; Dorati, R.; Genta, I.; Chiesa, E.; Pisani, S.; Conti, B. Skin Wound Healing Process and New Emerging Technologies for Skin Wound Care and Regeneration. Pharmaceutics 2020, 12, 735. [CrossRef] [PubMed]

4. Colalto, C. What phytotherapy needs: Evidence-based guidelines for better clinical practice. Phytother. Res. 2018, 32, 413-425. [CrossRef] 
5. Danciu, C.; Zupko, I.; Bor, A.; Schwiebs, A.; Radeke, H.; Hancianu, M.; Cioanca, O.; Alexa, E.; Oprean, C.; Bojin, F.; et al. Botanical Therapeutics: Phytochemical Screening and Biological Assessment of Chamomile, Parsley and Celery Extracts against A375 Human Melanoma and Dendritic Cells. Int. J. Mol. Sci. 2018, 19, 3624. [CrossRef]

6. Watson, L.E.; Bates, P.L.; Evans, T.M.; Unwin, M.M.; Estes, J.R. Molecular phylogeny of Subtribe Artemisiinae (Asteraceae), including Artemisia and its allied and segregate genera. BMC Evol. Biol. 2002, 2, 17. [CrossRef]

7. Lou, H.; Huang, Y.; Ouyang, Y.; Zhang, Y.; Xi, L.; Chu, X.; Wang, Y.; Wang, C.; Zhang, L. Artemisia annua sublingual immunotherapy for seasonal allergic rhinitis: A randomized controlled trial. Allergy 2020, 75, 2026-2036. [CrossRef]

8. Bora, K. Phytochemical and pharmacological potential of Artemisia absinthium Linn. and Artemisia asiatica Nakai: A Review. J. Pharm. Res. 2010, 3, 325-328.

9. Taleghani, A.; Emami, S.A.; Tayarani-Najaran, Z. Artemisia: A promising plant for the treatment of cancer. Bioorg. Med. Chem. 2020, 28, 115180. [CrossRef]

10. Czechowski, T.; Larson, T.R.; Catania, T.M.; Harvey, D.; Wei, C.; Essome, M.; Brown, G.D.; Graham, I.A. Detailed Phytochemical Analysis of High- and Low Artemisinin-Producing Chemotypes of Artemisia annua. Front. Plant Sci. 2018, 9, 641. [CrossRef]

11. Messaili, S.; Colas, C.; Fougère, L.; Destandau, E. Combination of molecular network and centrifugal partition chromatography fractionation for targeting and identifying Artemisia annua L. antioxidant compounds. J. Chromatogr. A 2019, 1615, 460785. [CrossRef]

12. Mohammadi, S.; Jafari, B.; Asgharian, P.; Martorell, M.; Sharifi-Rad, J. Medicinal plants used in the treatment of Malaria: A key emphasis to Artemisia, Cinchona, Cryptolepis, and Tabebuia genera. Phytother. Res. 2020, 34, 1556-1569. [CrossRef] [PubMed]

13. Foglio, M.A.; Dias, P.C.; Antônio, M.A.; Possenti, A.; Rodrigues, R.A.F.; da Silva, É.F.; Rehder, V.L.; de Carvalho, J.E. Antiulcerogenic Activity of Some Sesquiterpene Lactones Isolated from Artemisia annua. Planta Med. 2002, 68, 515-518. [CrossRef] [PubMed]

14. Yu, Y.; Simmler, C.; Kuhn, P.; Poulev, A.; Raskin, I.; Ribnicky, D.; Floyd, Z.E.; Pauli, G.F. The DESIGNER Approach Helps Decipher the Hypoglycemic Bioactive Principles of Artemisia dracunculus (Russian Tarragon). J. Nat. Prod. 2019, 82, 3321-3329. [CrossRef] [PubMed]

15. Durić, K.; Kovac Besovic, E.E.; Niksic, H.; Muratovic, S.; Sofic, E. Anticoagulant activity of some Artemisia dracunculus leaf extracts. Bosn. J. Basic Med. Sci. 2015, 15, 9-14. [CrossRef]

16. Kordali, S.; Kotan, R.; Mavi, A.; Cakir, A.; Ala, A.; Yildirim, A. Determination of the Chemical Composition and Antioxidant Activity of the Essential Oil of Artemisia dracunculus and of the Antifungal and Antibacterial Activities of Turkish Artemisia absinthium, A. dracunculus, Artemisia santonicum, and Artemisia spicigera Essential Oils. J. Agric. Food Chem. 2005, 53, 9452-9458. [CrossRef]

17. Ekiert, H.; Świątkowska, J.; Knut, E.; Klin, P.; Rzepiela, A.; Tomczyk, M.; Szopa, A. Artemisia dracunculus (Tarragon): A Review of Its Traditional Uses, Phytochemistry and Pharmacology. Front. Pharmacol. 2021, 12, 653993. [CrossRef]

18. Szopa, A.; Pajor, J.; Klin, P.; Rzepiela, A.; Elansary, H.O.; Al-Mana, F.A.; Mattar, M.A.; Ekiert, H. Artemisia absinthium L.Importance in the History of Medicine, the Latest Advances in Phytochemistry and Therapeutical, Cosmetological and Culinary Uses. Plants 2020, 9, 1063. [CrossRef]

19. Moacă, A.-E.; Pavel, I.Z.; Danciu, C.; Crăiniceanu, Z.; Minda, D.; Ardelean, F.; Antal, D.S.; Ghiulai, R.; Cioca, A.; Derban, M.; et al. Romanian Wormwood (Artemisia absinthium L.): Physicochemical and Nutraceutical Screening. Molecules 2019, $24,3087$. [CrossRef]

20. Asghar, M.N.; Khan, I.U.; Bano, N. In vitro antioxidant and radical-scavenging capacities of Citrullus colocynthes (L) and Artemisia absinthium extracts using promethazine hydrochloride radical cation and contemporary assays. Food Sci. Technol. Int. 2011, 17, 481-494. [CrossRef]

21. Guarrera, P.M. Traditional antihelmintic, antiparasitic and repellent uses of plants in Central Italy. J. Ethnopharmacol. 1999, 68, 183-192. [CrossRef]

22. Kharoubi, O.; Slimani, M.; Aoues, A. Neuroprotective effect of wormwood against lead exposure. J. Emerg. Trauma Shock 2011, 4, 82. [CrossRef]

23. Carvalho, A.R.; Diniz, R.M.; Suarez, M.A.M.; Figueiredo, C.S.S.e.S.; Zagmignan, A.; Grisotto, M.A.G.; Fernandes, E.S.; da Silva, L.C.N. Use of Some Asteraceae Plants for the Treatment of Wounds: From Ethnopharmacological Studies to Scientific Evidences. Front. Pharmacol. 2018, 9, 784. [CrossRef] [PubMed]

24. Mastrullo, V.; Cathery, W.; Velliou, E.; Madeddu, P.; Campagnolo, P. Angiogenesis in tissue engineering: As nature intended? Front. Bioeng. Biotechnol. 2020, 8, 188. [CrossRef]

25. Morbidelli, L.; Genah, S.; Cialdai, F. Effect of Microgravity on Endothelial Cell Function, Angiogenesis, and Vessel Remodeling During Wound Healing. Front. Bioeng. Biotechnol. 2021, 9, 720091. [CrossRef]

26. Morbidelli, L.; Terzuoli, E.; Donnini, S. Use of Nutraceuticals in Angiogenesis-Dependent Disorders. Molecules 2018, $23,2676$. [CrossRef] [PubMed]

27. Matusz, P.; Dragoslav Miclăuş, G.; Dragoş Banciu, C.; Sas, I.; Joseph, S.C.; Cornel Pirtea, L.; Shane Tubbs, R.; Loukas, M. Congenital Solitary Kidney with Multiple Renal Arteries: Case Report Using MDCT Angiography. Rom. J. Morphol. Embryol. 2015, 56, 823-826. [PubMed]

28. Ribatti, D.; Annese, T.; Tamma, R. The use of the chick embryo CAM assay in the study of angiogenic activity of biomaterials. Microvasc. Res. 2020, 131, 104026. [CrossRef] 
29. Moreno-Jiménez, I.; Hulsart-Billstrom, G.; Lanham, S.A.; Janeczek, A.A.; Kontouli, N.; Kanczler, J.M.; Evans, N.D.; Oreffo, R.O.C. The Chorioallantoic Membrane (CAM) Assay for the Study of Human Bone Regeneration: A Refinement Animal Model for Tissue Engineering. Sci. Rep. 2016, 6, 32168. [CrossRef]

30. Singleton, V.L.; Orthofer, R.; Lamuela-Raventós, R.M. Analysis of total phenols and other oxidation substrates and antioxidants by means of Folin-Ciocalteu reagent. Methods Enzymol. 1999, 299, 152-178. [CrossRef]

31. Gupta, D.; Gupta, R.K. Bioprotective properties of Dragon's blood resin: In vitro evaluation of antioxidant activity and antimicrobial activity. BMC Complement. Altern. Med. 2011, 11, 13. [CrossRef] [PubMed]

32. Moacă, E.A.; Farcaş, C.; Ghiţu, A.; Coricovac, D.; Popovici, R.; Cărăba-Meiţă, N.L.; Ardelean, F.; Antal, D.S.; Dehelean, C.; Avram, S.A. Comparative Study of Melissa officinalis Leaves and Stems Ethanolic Extracts in terms of Antioxidant, Cytotoxic, and Antiproliferative Potential. Evid. Based Complement. Altern. Med. 2018, 2018, 7860456. [CrossRef] [PubMed]

33. Santos, U.P.; Campos, J.F.; Torquato, H.F.V.; Paredes-Gamero, E.J.; Carollo, C.A.; Estevinho, L.M.; de Picoli Souza, K.; Dos Santos, E.L. Antioxidant, antimicrobial and cytotoxic properties as well as the phenolic content of the extract from Hancornia speciosa gomes. PLoS ONE 2016, 11, e0167531. [CrossRef] [PubMed]

34. Ghiulai, R.; Avram, S.; Stoian, D.; Pavel, I.Z.; Coricovac, D.; Oprean, C.; Vlase, L.; Farcas, C.; Mioc, M.; Minda, D.; et al. Lemon Balm Extracts Prevent Breast Cancer Progression In Vitro and In Ovo on Chorioallantoic Membrane Assay. Evid. Based Complement. Altern. Med. 2020, 2020, 6489159. [CrossRef] [PubMed]

35. Sipos, S.; Moacă, E.A.; Pavel, I.Z.; Avram, Ş.; Crețu, O.M.; Coricovac, D.; Racoviceanu, R.M.; Ghiulai, R.; Pană, R.D.; Şoica, C.M.; et al. Melissa officinalis L. Aqueous Extract Exerts Antioxidant and Antiangiogenic Effects and Improves Physiological Skin Parameters. Molecules 2021, 26, 2369. [CrossRef]

36. Baiceanu, E.; Vlase, L.; Baiceanu, A.; Nanes, M.; Rusu, D.; Crisan, G. New polyphenols identified in Artemisiae abrotani herba extract. Molecules 2015, 20, 11063-11075. [CrossRef]

37. Coșarcă, S.L.; Moacă, E.A.; Tanase, C.; Muntean, D.L.; Pavel, I.Z.; Dehelean, C.A. Spruce and Beech Bark Aqueous Extracts: Source of Polyphenols, Tannins And Antioxidants Correlated to In Vitro Antitumor Potential on Two Different Cell Lines. Wood Sci. Technol. 2019, 53, 313-333. [CrossRef]

38. Ghitu, A.; Schwiebs, A.; Radeke, H.H.; Avram, S.; Zupko, I.; Bor, A.; Pavel, I.Z.; Dehelean, C.A.; Oprean, C.; Bojin, F.; et al. A Comprehensive Assessment of Apigenin as an Antiproliferative, Proapoptotic, Antiangiogenic and Immunomodulatory Phytocompound. Nutrients 2019, 11, 858. [CrossRef]

39. Farcas, C.G.; Dehelean, C.; Pinzaru, I.A.; Mioc, M.; Socoliuc, V.; Moaca, E.-A.; Avram, S.; Ghiulai, R.; Coricovac, D.; Pavel, I.; et al. Thermosensitive Betulinic Acid-Loaded Magnetoliposomes: A Promising Antitumor Potential for Highly Aggressive Human Breast Adenocarcinoma Cells under Hyperthermic Conditions. Int. J. Nanomed. 2020, 15, 8175-8200. [CrossRef]

40. Felice, F.; Zambito, Y.; Belardinelli, E.; Fabiano, A.; Santoni, T.; Di Stefano, R. Effect of different chitosan derivatives on in vitro scratch wound assay: A comparative study. Int. J. Biol. Macromol. 2015, 76, 236-241. [CrossRef]

41. Ribatti, D. The chick embryo chorioallantoic membrane in the study of tumor angiogenesis. Rom. J. Morphol. Embryol. 2008, 49, 131-135. [PubMed]

42. Caunii, A.; Oprean, C.; Cristea, M.; Ivan, A.; Danciu, C.; Tatu, C.; Paunescu, V.; Marti, D.; Tzanakakis, G.; Spandidos, D.; et al. Effects of Ursolic and Oleanolic on SK-MEL-2 Melanoma Cells: In Vitro and In Vivo Assays. Int. J. Oncol. 2017, 51, 1651-1660. [CrossRef] [PubMed]

43. Scheel, J.; Kleber, M.; Kreutz, J.; Lehringer, E.; Mehling, A.; Reisinger, K.; Steiling, W. Eye Irritation Potential: Usefulness of the HET-CAM under the Globally Harmonized System of Classification and Labeling of Chemicals (GHS). Regul. Toxicol. Pharmacol. 2011, 59, 471-492. [CrossRef]

44. Szuhanek, C.A.; Watz, C.G.; Avram, S.; Moacă, E.-A.; Mihali, C.V.; Popa, A.; Campan, A.A.; Nicolov, M.; Dehelean, C.A. Comparative Toxicological In Vitro and In Ovo Screening of Different Orthodontic Implants Currently Used in Dentistry. Materials 2020, 13, 5690. [CrossRef] [PubMed]

45. Coricovac, D.; Farcas, C.; Nica, C.; Pinzaru, I.; Simu, S.; Stoian, D.; Soica, C.; Proks, M.; Avram, S.; Navolan, D.; et al. Ethinylestradiol and Levonorgestrel as Active Agents in Normal Skin, and Pathological Conditions Induced by UVB Exposure: In Vitro and In Ovo Assessments. Int. J. Mol. Sci. 2018, 19, 3600. [CrossRef]

46. Interagency Coordinating Committee on the Validation of Alternative Methods (ICCVAM), ICCVAM Recommended Test Method Protocol: Hen's Egg Test-Chorioallantoic Membrane. 2010. Available online: http://iccvam.niehs.nih.gov/ (accessed on 6 December 2021).

47. Wilson, T.D.; Steck, W.F. A Modified HET-CAM Assay Approach to the Assessment of Anti-Irritant Properties of Plant Extracts. Food Chem. Toxicol. 2000, 38, 867-872. [CrossRef]

48. Ribatti, D. The Chick Embryo Chorioallantoic Membrane (CAM). A Multifaceted Experimental Model. Mech. Dev. 2016, 141, 70-77. [CrossRef]

49. Luepke, N.P. Hen's Egg Chorioallantoic Membrane Test for Irritation Potential. Food Chem. Toxicol. 1985, 23, 287-291. [CrossRef]

50. Lordani, T.V.A.; de Lara, C.E.; Ferreira, F.B.P.; de Souza Terron Monich, M.; da Silva, C.M.; Lordani, C.R.F.; Bueno, F.G.; Teixeira, J.J.V.; Lonardoni, M.V.C. Therapeutic Effects of Medicinal Plants on Cutaneous Wound Healing in Humans: A Systematic Review. Mediat. Inflamm. 2018, 2018, 7354250. [CrossRef] 
51. Noroozi, R.; Sadeghi, E.; Yousefi, H.; Taheri, M.; Sarabi, P.; Dowati, A.; Ayatallahi, S.A.; Noroozi, R.; Ghafouri-Fard, S. Wound Healing Features of Prosopis farcta: In Vitro Evaluation of Antibacterial, Antioxidant, Proliferative and Angiogenic Properties. Gene Rep. 2019, 17, 100482. [CrossRef]

52. Sharma, A.; Khanna, S.; Kaur, G.; Singh, I. Medicinal Plants and Their Components for Wound Healing Applications. Future J. Pharm. Sci 2021, 7, 1-13. [CrossRef]

53. Bora, K.S.; Sharma, A. The Genus Artemisia: A Comprehensive Review. Pharm. Biol. 2011, 49, 101-109. [CrossRef] [PubMed]

54. Iqbal, S.; Younas, U.; Chan, K.W.; Zia-Ul-Haq, M.; Ismail, M. Chemical Composition of Artemisia annua L. Leaves and Antioxidant Potential of Extracts as a Function of Extraction Solvents. Molecules 2012, 17, 6020-6032. [CrossRef] [PubMed]

55. Kozlowska, M.; Scibisz, I.; Przybyl, J.L.; Ziarno, M.; Zbikowska, A.; Majewska, E. Phenolic Contents and Antioxidant Activity of Extracts of Selected Fresh and Dried Herbal Materials. Pol. J. Food Nutr. Sci. 2021, 71, 269-278. [CrossRef]

56. Ulewicz-Magulska, B.; Wesolowski, M. Total Phenolic Contents and Antioxidant Potential of Herbs Used for Medical and Culinary Purposes. Plant Foods Hum. Nutr. 2019, 74, 61-67. [CrossRef]

57. Msaada, K.; Salem, N.; Bachrouch, O.; Bousselmi, S.; Tammar, S.; Alfaify, A.; Al Sane, K.; Ben Ammar, W.; Azeiz, S.; Haj Brahim, A.; et al. Chemical Composition and Antioxidant and Antimicrobial Activities of Wormwood (Artemisia absinthium L.) Essential Oils and Phenolics. J. Chem. 2015, 2015, 804658. [CrossRef]

58. Ebrahimzadeh, M.A.; Nabavi, S.F.; Nabavi, S.M.; Pourmorad, F. Nitric Oxide Radical Scavenging Potential of Some Elburz Medicinal Plants. Afr. J. Biotechnol. 2010, 9, 5212-5217. [CrossRef]

59. Bora, K.; Sharma, A. Pharmaceutical Biology Evaluation of Antioxidant and Free-Radical Scavenging Potential of Artemisia absinthium. Pharm. Biol. 2011, 49, 1216-1223. [CrossRef]

60. Kim, W.S.; Choi, W.J.; Lee, S.; Kim, W.J.; Lee, D.C.; Sohn, U.D.; Shin, H.S.; Kim, W. Anti-Inflammatory, Antioxidant and Antimicrobial Effects of Artemisinin Extracts from Artemisia annua L. Korean J. Physiol. Pharmacol. 2015, 19, 21-27. [CrossRef]

61. Khezrilu Bandli, J.; Heidari, R. The Evaluation of Antioxidant Activities and Phenolic Compounds in Leaves and Inflorescence of Artemisia dracunculus L. by HPLC. J. Med. Plants 2014, 13, 41-50.

62. Emami, S.A.; Asili, J.; Mohagheghi, Z.; Hassanzadeh, M.K. Antioxidant activity of leaves and fruits of Iranian conifers. Evid. Based Complement. Altern. Med. 2007, 4, 313-319. [CrossRef] [PubMed]

63. Ivanescu, B.; Vlase, L.; Corciova, A.; Lazar, M.I. Artemisinin Evaluation in Romanian Artemisia annua Wild Plants Using a New HPLC/MS Method. Nat. Prod. Res. 2011, 25, 716-722. [CrossRef] [PubMed]

64. Moghadam, S.E.; Ebrahimi, S.N.; Salehi, P.; Farimani, M.M.; Hamburger, M.; Jabbarzadeh, E. Wound Healing Potential of Chlorogenic Acid and Myricetin-3-o- $\beta$-Rhamnoside Isolated from Parrotia persica. Molecules 2017, 22, 1501. [CrossRef]

65. Song, Y.; Desta, K.T.; Kim, G.S.; Lee, S.J.; Lee, W.S.; Kim, Y.H.; Jin, J.S.; Abd El-Aty, A.M.; Shin, H.C.; Shim, J.H.; et al. Polyphenolic profile and antioxidant effects of various parts of Artemisia annua L. Biomed. Chromatogr. 2016, 30, 588-595. [CrossRef] [PubMed]

66. Mumivand, H.; Babalar, M.; Tabrizi, L.; Craker, L.E.; Shokrpour, M.; Hadian, J. Antioxidant properties and principal phenolic phytochemicals of Iranian tarragon (Artemisia dracunculus L.) accessions. Hortic. Environ. Biotechnol. 2017, 58, 414-422. [CrossRef]

67. Oh, C.T.; Jang, Y.J.; Kwon, T.R.; Im, S.; Kim, S.R.; Seok, J.; Kim, G.Y.; Kim, Y.H.; Mun, S.K.; Kim, B.J. Effect of isosecotanapartholide isolated from Artemisia princeps Pampanini on IL-33 production and STAT-1 activation in HaCaT keratinocytes. Mol. Med. Rep. 2017, 15, 2681-2688. [CrossRef]

68. Kim, E.J.; Kim, G.T.; Kim, B.M.; Lim, E.G.; Kim, S.Y.; Kim, Y.M. Apoptosis-induced effects of extract from Artemisia annua Linné by modulating PTEN/p53/PDK1/Akt/ signal pathways through PTEN/p53-independent manner in HCT116 colon cancer cells. BMC Complement. Altern. Med. 2017, 17, 236. [CrossRef]

69. Yang, J.H.; Lee, E.; Lee, B.; Cho, W.K.; Ma, J.Y.; Park, K.I. Ethanolic Extracts of Artemisia apiacea Hance Improved Atopic DermatitisLike Skin Lesions In Vivo and Suppressed TNF-Alpha/IFN-Gamma-Induced Proinflammatory Chemokine Production In Vitro. Nutrients 2018, 10, 806. [CrossRef]

70. Ivanov, M.; Gašić, U.; Stojković, D.; Kostić, M.; Mišić, D.; Soković, M. New Evidence for Artemisia absinthium L. Application in Gastrointestinal Ailments: Ethnopharmacology, Antimicrobial Capacity, Cytotoxicity, and Phenolic Profile. Evid. Based Complement. Altern. Med. 2021, 2021, 9961089. [CrossRef]

71. Gaspar-Pintiliescu, A.; Seciu, A.M.; Miculescu, F.; Moldovan, L.; Ganea, E.; Craciunescu, O. Enhanced Extracellular Matrix Synthesis Using Collagen Dressings Loaded with Artemisia absinthium Plant Extract. J. Bioact. Compat. Polym. 2018, 33, 516-528. [CrossRef]

72. Lee, S.Y.; Nam, S.; Hong, I.K.; Kim, H.; Yang, H.; Cho, H.J. Antiproliferation of Keratinocytes and Alleviation of Psoriasis by the Ethanol Extract of Artemisia capillaris. Phytother. Res. 2018, 32, 923-932. [CrossRef] [PubMed]

73. Chang, J.W.; Hwang, H.S.; Kim, Y.S.; Kim, H.J.; Shin, Y.S.; Jittreetat, T.; Kim, C.H. Protective Effect of Artemisia asiatica (Pamp.) Nakai Ex Kitam Ethanol Extract against Cisplatin-Induced Apoptosis of Human HaCaT Keratinocytes: Involvement of NF-Kappa B- and Bcl-2-Controlled Mitochondrial Signaling. Phytomedicine 2015, 22, 679-688. [CrossRef] [PubMed]

74. Boudjelal, A.; Smeriglio, A.; Ginestra, G.; Denaro, M.; Trombetta, D. Phytochemical Profile, Safety Assessment and Wound Healing Activity of Artemisia absinthium L. Plants 2020, 9, 1744. [CrossRef] [PubMed]

75. Ranjbar, R.; Yousefi, A. Artemisia Dracunculus in Combination with Chitosan Nanoparticle Biofilm Improves Wound Healing in MRSA Infected Excisional Wounds: An Animal Model Study. EurAsian J. Biosci. 2018, 12, 219-226.

76. Abdolmaleki, Z.; Arab, H.A.; Amanpour, S.; Muhammadnejad, S. Anti-Angiogenic Effects of Ethanolic Extract of Artemisia sieberi Compared to Its Active Substance, Artemisinin. Rev. Bras. Farmacogn. 2016, 26, 326-333. [CrossRef] 
77. Yoon, M.; Kim, M.Y. The Anti-Angiogenic Herbal Composition Ob-X from Morus alba, Melissa officinalis, and Artemisia capillaris Regulates Obesity in Genetically Obese Ob/Ob Mice. Pharm. Biol. 2011, 49, 614-619. [CrossRef]

78. Jaouadi, I.; Tansu Koparal, A.; Beklem Bostancığlu, R.; Tej Yakoubi, M.; el Gazzah, M. The Anti-Angiogenic Activity of Artemisia herba-alba's Essential Oil and Its Relation with the Harvest Period. AJCS 2014, 8, 1395-1401.

79. Zhu, X.X.; Yang, L.; Li, Y.J.; Zhang, D.; Chen, Y.; Kostecká, P.; Kmoníéková, E.; Zídek, Z. Effects of Sesquiterpene, Flavonoid and Coumarin Types of Compounds from Artemisia annua L. on Production of Mediators of Angiogenesis. Pharmacol. Rep. 2013, 65, 410-420. [CrossRef]

80. Feng, X.; Cao, S.; Qiu, F.; Zhang, B. Traditional Application and Modern Pharmacological Research of Artemisia annua L. Pharmacol. Ther. 2020, 216, 107650. [CrossRef]

81. Majewska, I.; Gendaszewska-Darmach, E. Proangiogenic Activity of Plant Extracts in Accelerating Wound Healing-A New Face of Old Phytomedicines. Acta Biochim. Pol. 2011, 58, 449-460. [CrossRef]

82. Tsakiroglou, P.; Vandenakker, N.E.; del Bo', C.; Riso, P.; Klimis-Zacas, D. Role of Berry Anthocyanins and Phenolic Acids on Cell Migration and Angiogenesis: An Updated Overview. Nutrients 2019, 11, 1075. [CrossRef] [PubMed] 